\title{
Mycobacterium tuberculosis complex genetic diversity: mining the fourth international spoligotyping database (SpoIDB4) for classification, population genetics and epidemiology
}

Karine Brudey ${ }^{1}$, Jeffrey R Driscoll ${ }^{2}$, Leen Rigouts ${ }^{3}$, Wolfgang M Prodinger ${ }^{4}$, Andrea Gori ${ }^{5}$, Sahal A Al-Hajoj ${ }^{6}$, , Caroline Allix ${ }^{7}$, Liselotte Aristimuño ${ }^{8}$, Jyoti Arora9 , Viesturs Baumanis ${ }^{10}$, Lothar Binder ${ }^{11}$, Patricia Cafrune ${ }^{12}$, Angel Cataldi ${ }^{13}$, Soonfatt Cheong ${ }^{14}$, Roland Diel ${ }^{15}$, Christopher Ellermeier ${ }^{16}$, Jason T Evans17, Maryse Fauville-Dufaux7, Séverine Ferdinand1, Dario Garcia de Viedma ${ }^{18}$, Carlo Garzelli ${ }^{19}$, Lidia Gazzola ${ }^{5}$, Harrison M Gomes ${ }^{20}$, M Cristina Guttierez ${ }^{21}$, Peter M Hawkey ${ }^{17}$, Paul D van Helden $^{22}$, Gurujaj V Kadival23, Barry N Kreiswirth ${ }^{24}$, Kristin Kremer ${ }^{25}$, Milan Kubin ${ }^{26}$, Savita P Kulkarni ${ }^{23}$, Benjamin Liens ${ }^{1}$, Troels Lillebaek27, Ho Minh Ly28, Carlos Martin²9, Christian Martin ${ }^{30}$, Igor Mokrousov², Olga Narvskaïa ${ }^{31}$, Yun Fong Ngeow ${ }^{14}$, Ludmilla Naumann ${ }^{32}$, Stefan Niemann ${ }^{33}$, Ida Parwati ${ }^{34}$, Zeaur Rahim ${ }^{35}$, Voahangy RasolofoRazanamparany ${ }^{36}$, Tiana Rasolonavalona ${ }^{36}$, M Lucia Rossetti ${ }^{12}$, Sabine RüschGerdes $^{33}$, Anna Sajduda 37 , Sofia Samper ${ }^{38}$, Igor G Shemyakin ${ }^{39}$, Urvashi B Singh ${ }^{9}$, Akos Somoskovi 40 , Robin A Skuce ${ }^{41}$, Dick van Soolingen ${ }^{25}$, Elisabeth M Streicher ${ }^{22}$, Philip N Suffys ${ }^{20}$, Enrico Tortoli ${ }^{42}$, Tatjana Tracevska ${ }^{10}$, Véronique Vincent ${ }^{21}$, Tommie C Victor ${ }^{22}$, Robin M Warren ${ }^{22}$, Sook Fan Yap ${ }^{14}$, Khadiza Zaman ${ }^{35}$, Françoise Portaels ${ }^{3}$, Nalin Rastogi*1 and Christophe Sola*1

Address: ${ }^{1}$ Unité de la Tuberculose et des Mycobactéries, Institut Pasteur de Guadeloupe, Guadeloupe, 2Wadsworth Center, New York State Dept. of Health, Albany, NY, USA, ${ }^{3}$ Mycobacteriology Unit, Prince Leopold Institute of Tropical Medicine, Antwerp, Belgium, ${ }^{4}$ Dept. Hygiene Microbiology and Social Medicine, Innsbruck Medical University, Innsbruck, Austria, ${ }^{5}$ Dept of Infectious Diseases, Institut of Infectious Diseases, Milano, Italy, ${ }^{6}$ Department of Comparative Medicine, King Faisal specialist Hospital and Research Center, Riyadh, Saudi Arabia, ${ }^{7}$ Laboratoire de la Tuberculose, Institut Pasteur de Bruxelles, Belgique, ${ }^{8}$ Universidad Centrooccidental Lisandro Alvarado, Barquisimeto, Venezuela and Universidad de Zaragoza, Spain, ${ }^{9}$ All India Institute of Medical Sciences, New Delhi, India, ${ }^{10}$ Biomedical Research and Study Center, Riga, Latvia, ${ }^{11}$ Institut for Hygiene, Microbiologie and Tropical Medicine, Austria, ${ }^{12}$ Universidade Federal do Rio Grande de Soul, Brazil, ${ }^{13}$ Instituto de Biotecnologia INTA, Castelar, Argentina, ${ }^{14}$ Dept of Medical Microbiology and Pathology, faculty of Medicine, University of Malaya, Kuala Lumpur, Malaysia, School of Public Health, ${ }^{15}$ University of Düsseldorf, Heinrich-Heine-University, Düsseldorf, ${ }^{16}$ Dept of Internal Medicine II, University of Regensbourg, Germany, ${ }^{17}$ Public Health Laboratory, Hearltlands Hospital, Birmingham, UK, ${ }^{18}$ Dept of Clinical Microbiology and Infectious Diseases, Hospital Gregorio Marañon, Madrid, Spain, ${ }^{19}$ Dept. of Experimental Pathology, Medical Biotechnology, Infection and Epidemiology, Pisa University, Pisa, Italy, ${ }^{20}$ Laboratory of Molecular Biology applied to Mycobacteria, Dept. Mycobacteriosis, Oswaldo Cruz Institute, Rio de Janeiro, Brazil, ${ }^{21}$ Centre National de Référence des Mycobactéries, Institut Pasteur, Paris, France, ${ }^{22}$ MRC Centre for Molecular and Cellular Biology, Dept of medical Biochemistry, University of Stellenbosch, Tygerberg, South Africa, ${ }^{23}$ Laboratory Nuclear Medicine Section, Isotope group, Bhabha Atomic Research Centre c/T.M.H. Annexe, Parel, Mumbai-400012, India, ${ }^{24}$ Public Health Research Institute, Newark, NJ, USA, ${ }^{25}$ Mycobacteria reference unit, Diagnostic Laboratory for Infectious Diseases and Perinatal Screening, National Institute of Public Health and the Environment, Bilthoven, The Netherlands, ${ }^{26}$ Municipal Institute of Hygiene, Prague, Czech Republic, ${ }^{27}$ Statens Serum Institute, Int. Ref. lab. for Mycobacteriology, Copenhagen Denmark, ${ }^{28}$ Institute of Hygiene and Epidemiology, Hanoi, Vietnam, ${ }^{29}$ Universidad de Zaragoza, Zaragoza, Spain, ${ }^{30}$ Laboratoire de Bactério-virologie-hygiène, CHU Dupuytren, Limoges, France, ${ }^{31}$ Institut Pasteur de Saint-Petersbourg, Saint Petersbourg, Russia, ${ }^{32}$ Bavarian Health and Food Safety Authority, Oberschleissheim, Germany, ${ }^{33}$ Forschungszentrum, National Reference Center for Mycobacteria, Borstel, Germany, ${ }^{34}$ Dept of Clinical Pathology, Padjadjaran University, Dr. Hasan Sadikin Hospital, Bandung, Indonesia, ${ }^{35}$ Tuberculosis Laboratory, International Centre for Diarrhoeal Research, Dhaka, Bangladesh, ${ }^{36}$ Institut Pasteur de Madagascar, Tananarive, Madagascar, ${ }^{37}$ Dept of Genetics of Microorganisms, University of Lódz, Lodz, Poland, ${ }^{38}$ Servicio Microbiología, Hospital Universitario Miguel Servet, Zaragoza, Spain, ${ }^{39}$ State Research Center for Applied Microbiology, Obolensk, Russian Federation, ${ }^{40}$ Dept. of Respiratory Medicine School of Medicine Semmelweis University, Budapest, Hungary, ${ }^{41}$ Veterinary Sciences Division, Department of agriculture for Northern Ireland, Belfast, UK and ${ }^{42}$ Centro regionale di Riferimento per i Micobatteri, Laboratorio de Microbiologia e Virologia, Ospedale Careggi, Firenze, Italy 
Published: 06 March 2006

BMC Microbiology2006, 6:23 doi:10.1186/147|-2180-6-23
Received: 08 November 2005

Accepted: 06 March 2006

This article is available from: http://www.biomedcentral.com/|47|-2/80/6/23

(C) 2006Brudey et al; licensee BioMed Central Ltd.

This is an Open Access article distributed under the terms of the Creative Commons Attribution License (http://creativecommons.org/licenses/by/2.0), which permits unrestricted use, distribution, and reproduction in any medium, provided the original work is properly cited.

\begin{abstract}
Background: The Direct Repeat locus of the Mycobacterium tuberculosis complex (MTC) is a member of the CRISPR (Clustered regularly interspaced short palindromic repeats) sequences family. Spoligotyping is the widely used PCR-based reverse-hybridization blotting technique that assays the genetic diversity of this locus and is useful both for clinical laboratory, molecular epidemiology, evolutionary and population genetics. It is easy, robust, cheap, and produces highly diverse portable numerical results, as the result of the combination of (I) Unique Events Polymorphism (UEP) (2) Insertion-Sequence-mediated genetic recombination. Genetic convergence, although rare, was also previously demonstrated. Three previous international spoligotype databases had partly revealed the global and local geographical structures of MTC bacilli populations, however, there was a need for the release of a new, more representative and extended, international spoligotyping database.
\end{abstract}

Results: The fourth international spoligotyping database, SpoIDB4, describes 1939 shared-types (STs) representative of a total of 39,295 strains from 122 countries, which are tentatively classified into 62 clades/lineages using a mixed expert-based and bioinformatical approach. The SpolDB4 update adds 26 new potentially phylogeographically-specific MTC genotype families. It provides a clearer picture of the current MTC genomes diversity as well as on the relationships between the genetic attributes investigated (spoligotypes) and the infra-species classification and evolutionary history of the species. Indeed, an independent Naïve-Bayes mixture-model analysis has validated main of the previous supervised SpoIDB3 classification results, confirming the usefulness of both supervised and unsupervised models as an approach to understand MTC population structure. Updated results on the epidemiological status of spoligotypes, as well as genetic prevalence maps on six main lineages are also shown. Our results suggests the existence of fine geographical genetic clines within MTC populations, that could mirror the passed and present Homo sapiens sapiens demographical and mycobacterial co-evolutionary history whose structure could be further reconstructed and modelled, thereby providing a large-scale conceptual framework of the global TB Epidemiologic Network.

Conclusion: Our results broaden the knowledge of the global phylogeography of the MTC complex. SpolDB4 should be a very useful tool to better define the identity of a given MTC clinical isolate, and to better analyze the links between its current spreading and previous evolutionary history. The building and mining of extended MTC polymorphic genetic databases is in progress.

\section{Background}

Each year, 9 million new cases of tuberculosis (TB) are recorded, of which 2 million result in fatality. Diagnostics, chemotherapy and vaccination are available, however, the disease is far from being eradicated [1]. Many genetic loci within the Mycobacterium tuberculosis complex (MTC) genomes are polymorphic and may be used for molecular evolutionary studies [2]. Among these, the Direct Repeat locus (DR), which consists of alternating identical DRs and variable spacers can be assessed using the "Spoligotyping" fingerprinting method thousands of different patterns [3]. DR loci are members of a universal family of sequences, designated as CRISPR [4], whose physiological role is poorly known $[5,6]$. Spoligotyping was previously shown to be useful for both clinical management and molecular epidemiology of MTC [7]. When used in association with variable-number of DNA tandem-repeat (VNTR) [8] or Mycobacterial-interspersed-repetitive-units (MIRU) [9], spoligotyping is a fast, robust, and cost effective genotyping technique, alternative to traditional IS6110-RFLP fingerprinting. These methods are also designated as MLVA (Multiple-locus variable number tandem repeats analysis) [10]. Since 1999, we have built and released genetic diversity databases of the MTC DR locus as an attempt to analyze MTC population structure, and to assess the complexity of global TB transmission and of the 
underlying spatial and temporal evolution of the TB genetic landscape. Indeed, previous studies have shown that the host's geographical origin is predictive of the clinical isolate of tuberculosis being carried, since there is an apparent stable association of TB bacilli populations with their human hosts in various environments [11], hence a strong phylogeographical clustering of TB bacilli population. We hypothesize that co-evolution between human beings and bacilli, and vertical transmission (in the household), must have been the main mode of tuberculosis transmission throughout centuries and even millenniums [12].

MTC organisms were also shown to evolve clonally [13]. Hence, the reconstruction of the population structure of this species may be an indirect way of assessing its main host's (Homo sapiens sapiens) migratory and demographic history [14]. Indeed, tuberculosis may have affected early hominids and it is tempting to speculate that the MTC originated in East-Africa [15]. Its expansion to the rest of the world may have coincided with the waves of human migration out of Africa, with potential back migration from Asia to Sub-Saharan Africa [16]. If the past phylogeny of MTC is likely to have involved horizontal gene transfer events, however, these events are no longer observed [17]. All these clues suggests the pioneer roles of geography, demography and human migration history in shaping today's MTC population structure [11]. Consequently, the current concepts of "natural evolving communities" or "clusters of bacilli", are important: (1) for TB epidemiology - as the global pandemia should be considered as a network of outbreaks of more or less circumscribed clones $[18,19]$ - (2) for molecular ecology, evolutionary and population genetics and phylogeography, - as today's MTC genomes are likely to include cryptic information on their passed and present history in their changing environments $[20,21]-$ and last but not least (3) for systematics and infra-species taxonomy [22]. The two first databases were poorly representative of the worldwide MTC diversity $[23,24]$, whereas the third update was already more representative $[25,26]$. Although these studies did not allow for a definitive rebuilding of the MTC limb and twig history of the TB tree, their use combined to bioinformatical data-mining methods, allowed to previously classify MTC in eight to ten main genetic lineages [27], a classification that has now been validated using SNPs $[28,29]$.

In this new study, we data-mined an updated SpolDB4 version, which contains 1939 STs representing a total of 39,295 clinical isolates originating from 122 countries. Considering the known diversity of the origin of patients, which was documented in some cases, SpolDB4 is representative of a total of 141 countries. The SpolDB4 update adds 1126 newly defined STs and provides a higher reso- lution picture of the worldwide MTC genome diversity assessed by spoligotyping. However, the new challenge is to link the genetic variability of MTC with the clinical variability of TB, whatever the setting, whether in high burden countries or in densely populated areas such as India or China.

\section{Results \\ Classification of spoligotypes \\ Classification of SpolDB4 spoligotype patterns into meaningful \\ lineages}

The listing of ST alleles with their distribution by country of location and a presumed sub lineage/lineage label is provided in additional file 1.51 new countries are represented in SpolDB4. Out of 39,295 spoligotypes patterns, $\mathrm{n}=35,925$ are found in 1939 STs ( $91.4 \%$ of the isolates, ) and $3370(8.6 \%)$ are orphan patterns, totalling 5,309 individual alleles. Two approaches, a statistical, and a mixed expert-based/bioinformatical one were used to data-mine SpolDB4 to classify spoligotypes. Results are summarized in Figure 1.

\section{Results obtained by the statistical approach}

The 20 most frequent STs totalled 17,701 isolates (49.3\% of the clustered isolates). The 50 most frequent STs increased clustering to $61.8 \%(\mathrm{n}=22,219)$. These 50 most frequent types are shown in figure 1 . Three types did not receive a lineage label, ST46, ST51 and ST210. ST46 and ST51 are patterns prone to genetic convergence, similarly as reported for ST4, whose ancestors can either be ST33 or ST34 [30]. ST210 (also designated as HN24, a Principal Genetic Group (PGG) 3 strain) was first described in a study done in Texas and is almost restricted to the USA [31]. The other 47 most prevalent spoligotypes belong to known genetic lineages or are defined variants.

\section{Results obtained by the mixed expert-based/bioinformatical approach}

Figure 1 also describes a total of 62 remarkable lineages/ sub lineages. This classification was obtained with the use of a dedicated software that search for similarities between patterns (SpolNet, P. Abdoul et al. unpublished, see material and methods section). Since SpolDB4 is a mixed $M$. tuberculosis (human) and M. bovis (human or bovine) isolates database, 237 STs were found to belong to the $M$. bovis subspecies $(\mathrm{n}=5710)$, whereas 1702 STs $(\mathrm{n}=$ $33,585)$ were not $M$. bovis. The calculation of the genetic diversity index " $\mathrm{H}$ " -defined as $\mathrm{H}=2 \mathrm{n}\left(1-\Sigma \mathrm{x}_{\mathrm{i}}^{2}\right) / 2 \mathrm{n}-1$ where $\mathrm{n}=$ number of individuals and $\mathrm{x}_{\mathrm{i}}$ is the frequency of the $i^{\text {th }}$ allele-gives a value of 0,98 . H only slightly improved $(+0.6 \%)$ compared to SpolDB3. This shows that the exponential increase of data was not reflected by the increase in bacterial diversity description, as most data were already known (over fitting phenomenon, a limitation of this study). Indeed, a quantitatively updated 


\begin{tabular}{|c|c|c|c|c|c|}
\hline ST $n^{\circ}$ & lineage/sublineage & Binary spoligotype & Octal ${ }^{* *}$ & Total & Frequency \\
\hline 181 & AFRI1 & " & 770777777777671 & 270 & 0.75 \\
\hline 331 & AFRI2 & ma & 774077607777071 & 74 & 20 \\
\hline 438 & AFRI3 & ובמנפבחה & 774077777777071 & 30 & 0.08 \\
\hline 1 & Beijing & 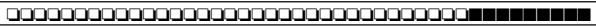 & 000000000003771 & 4051 & 11.28 \\
\hline 482 & BOV1 & 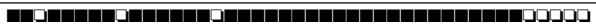 & 676773777777600 & 2401 & 6.68 \\
\hline 683 & BOV2 & 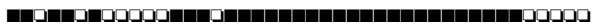 & 664073777777600 & 2770 & 7.71 \\
\hline 479 & BOV3 & 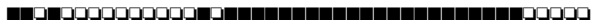 & 640013777777600 & 204 & 0.57 \\
\hline 647 & BOV4 & 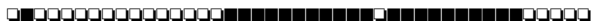 & 200003777377600 & 166 & 0.46 \\
\hline 691 & BOV1-variant 1 & טמבם & 676573777777600 & $175^{*}$ & $0.48^{*}$ \\
\hline 665 & BOV1- variant2 & שدמ & 616773777777600 & $120^{*}$ & $0.33^{*}$ \\
\hline 676 & BOV2-variant1 & טמנם & 664073774037600 & $177^{\star}$ & $0.49^{*}$ \\
\hline 679 & BOV2-variant2 & 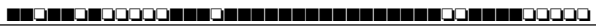 & 664073777763600 & $428^{*}$ & $1.19^{*}$ \\
\hline 592 & canettii & 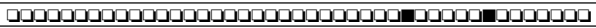 & 000000000101000 & 9 & 0.03 \\
\hline 26 & CAS1-Delhi & 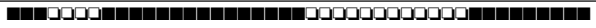 & 703777740003771 & 1076 & 3 \\
\hline 21 & CAS1-Kili & 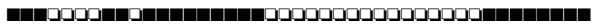 & 703377400001771 & 158 & 0.44 \\
\hline 25 & CAS1-variant & וחבמבמכנ & 703777740003171 & $128^{*}$ & $0.35^{*}$ \\
\hline 288 & CAS2 & 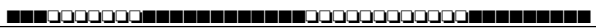 & 700377740003771 & 79 & 0.22 \\
\hline 405 & Zero & 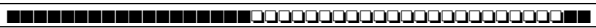 & 777777000000011 & 19 & 0.05 \\
\hline 100 & MANU1 & mant & 777777777773771 & 75 & 0.21 \\
\hline 54 & MANU2 & & 777777777763771 & 160 & 0.45 \\
\hline 1378 & MANU3 & 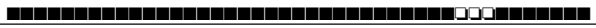 & 777777777770771 & 28 & 0.08 \\
\hline 539 & microti & 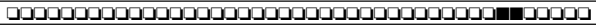 & 000000000000600 & 38 & 0.11 \\
\hline 593 & PINI1 & 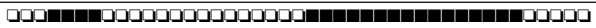 & 074000037777600 & 11 & 0.03 \\
\hline 637 & PINI2 & 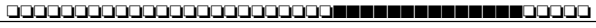 & 000000007777600 & 93 & 0.26 \\
\hline 236 & EAI-5 & יחרחק & 777777777413771 & 1014 & 2.82 \\
\hline 48 & EAI1-SOM & m & 777777777413731 & 450 & 1.25 \\
\hline 19 & EAI2-Manilla & m & 677777477413771 & 544 & 1.51 \\
\hline 89 & EA12-Nonthaburi & ובחמבטد & 674000003413771 & 72 & 0.2 \\
\hline 11 & EAI3-IND & m. & 477777777413071 & 432 & 1.2 \\
\hline 139 & EAl4-VNM & & 777777774413771 & 347 & 0.97 \\
\hline 591 & EAI6-BGD1 & m & 777777757413771 & 169 & 0.47 \\
\hline 1898 & EAI7-BGD2 & שחטבמ & 777777770003371 & 68 & 0.19 \\
\hline 109 & EAI8-MDG & 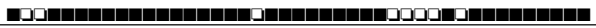 & 477777377413771 & 63 & 0.17 \\
\hline 47 & $\mathrm{H} 1$ & 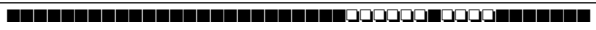 & 777777774020771 & 1236 & 3.44 \\
\hline 62 & H1-variant1 & 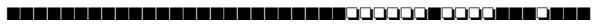 & 777777774020731 & $171^{*}$ & $0.44^{*}$ \\
\hline 2 & H2 & 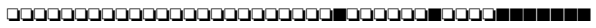 & 000000004020771 & 296 & 0.82 \\
\hline 50 & H3 & ובמנد & 7777777777720771 & 1963 & 5.46 \\
\hline 127 & $\mathrm{H} 4$ & במבנ] & 577777777420771 & 374 & 1.04 \\
\hline 20 & LAM01 & 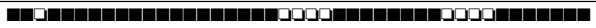 & 677777607760771 & 484 & 1.35 \\
\hline 17 & LAM02 & 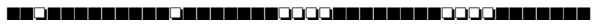 & 677737607760771 & 411 & 1.14 \\
\hline 33 & LAM03 & إمدد & 776177607760771 & 509 & 1.42 \\
\hline 60 & LAM04 & 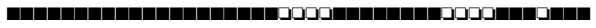 & 777777607760731 & 148 & 0.41 \\
\hline 93 & LAM05 & הובמכו & 777737607760771 & 264 & 0.73 \\
\hline 64 & LAM06 & המבנ & 777777607560771 & 172 & 0.48 \\
\hline 41 & LAM07-TUR & ובמנد & 777777404760771 & 160 & 0.45 \\
\hline 290 & LAM08 & וספבמ & 777777606760771 & 22 & 0.06 \\
\hline 42 & LAM09 & 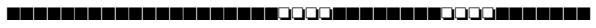 & 777777607760771 & 1930 & 5.37 \\
\hline 61 & LAM10-CAM & ובמدנ & 777777743760771 & 432 & 1.2 \\
\hline 59 & LAM11-ZWE & 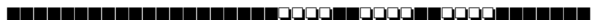 & 777777606060771 & 240 & 0.67 \\
\hline 209 & LAM12-Madrid1 & 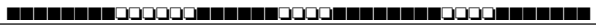 & 776017607760771 & 24 & 0.07 \\
\hline 53 & T1 & " & 777777777760771 & 6412 & 17.85 \\
\hline 280 & T1-RUS2 & במנמנמבטد & 770000777760771 & 63 & 0.18 \\
\hline 34 & $\mathrm{~s}$ & שחבמבה & 776377777760771 & 648 & 1.8 \\
\hline 52 & T2 & ומנدב & 777777777760731 & 840 & 2.34 \\
\hline 135 & T2-Uganda & במבد & 777777777760730 & 48 & 0.13 \\
\hline 37 & T3 & הובמכו & 777737777760771 & 277 & 0.77 \\
\hline 149 & T3-ETH & ובמבני & 777000377760771 & 221 & 0.62 \\
\hline 40 & T4 & מטבמ & 777777377760771 & 168 & 0.47 \\
\hline 39 & T4-CEU1 & הובמב & 777777347760471 & 133 & 0.37 \\
\hline 44 & T5 & ובמנם & 777777757760771 & 298 & 0.83 \\
\hline 58 & T5-Madrid2 & 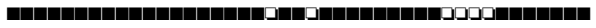 & 777777557760771 & 103 & 0.29 \\
\hline 254 & T5-RUS1 & 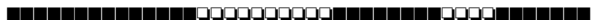 & 777760007760771 & 100 & 0.28 \\
\hline 1737 & Tuscany & 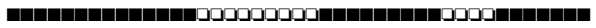 & 777760017760771 & 11 & 0.03 \\
\hline 451 & H37Rv & הבמנטו & 777777477760771 & 147 & 0.41 \\
\hline 627 & T3-OSA & 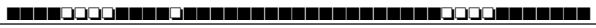 & 741737777760771 & 19 & 0.05 \\
\hline 119 & $\mathrm{x} 1$ & 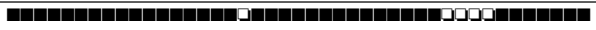 & 777776777760771 & 956 & 2.66 \\
\hline 137 & $\mathrm{x} 2$ & 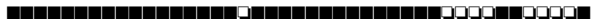 & 777776777760601 & 1069 & 2.98 \\
\hline 38 & X2-variant1 & 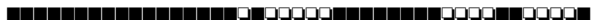 & 777776407760601 & $125^{*}$ & $0.34^{*}$ \\
\hline 92 & x3 & 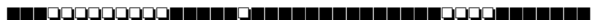 & 700076777760771 & 699 & 1.95 \\
\hline 91 & X3-variant1 & 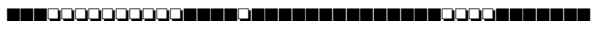 & 700036777760771 & $143^{*}$ & $0.39^{*}$ \\
\hline 197 & X3-variant2 & 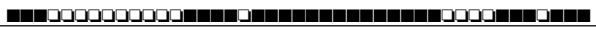 & 700036777760731 & $244^{*}$ & $0.67^{*}$ \\
\hline 51 & undesignated & 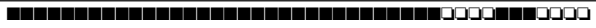 & 777777777760700 & $158^{*}$ & $0.43^{*}$ \\
\hline 4 & LAM $3 / \mathrm{S}$ & 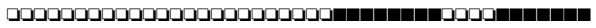 & 000000007760771 & $118^{*}$ & $0.32^{*}$ \\
\hline 73 & T3-variant & 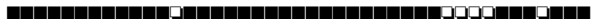 & 777737777760731 & $114^{*}$ & $0.32^{*}$ \\
\hline 210 & undesignated & |- & 776037777760771 & $104^{*}$ & $0.29^{*}$ \\
\hline 49 & H3-variant & 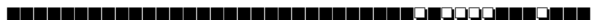 & 777777777720731 & $102^{*}$ & $0.28^{\star}$ \\
\hline 46 & undesignated & 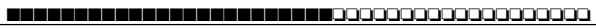 & 777777770000000 & $95^{*}$ & $0.26^{*}$ \\
\hline
\end{tabular}

Figure I

Bioinformatical (62 lineages/sub lineages prototype patterns) and statistical (50 most frequent) classification analysis of SpoIDB4. First column ST $\mathrm{n}^{\circ}$ : Shared-type (ST) number of prototype pattern for the linage/sub lineage. Second column: lineage/ sub lineage name. Third column: Binary spoligo display with black-white squares for respectively hybridizing-non-hybridizing spacers. Fourth column: Octal code (in red: defining octal rule). Fifth column: total absolute number of isolates of the subclass when variant ST spoligos are included (using SpolNet). Sixth column: same but expressed as percentage of total clustered isolates. * Total number and Frequency for these types are already included in their mother clade if known. Undesignated types are counted within the TI-ill-defined lineage. ** in red: octal rule defining the genotype. 
SpolDB3 (on 817 STs) would cluster 31,292 isolates, whereas the new 1122 STs aggregate only 4633 additional clustered isolates. Further improvement of $\mathrm{H}$ would require new data entries, possibly from yet unrepresented settings and/or high TB-burden countries such as India and China.

\section{New genetic lineages within $M$. tuberculosis complex} SpolDB4 defines 62 genetic lineages/sub lineages (figure $1)$. M. bovis strains were divided in 3 sub lineages corresponding to ST prototypes 482, 683 and 479. A new signature for $M$. microti is suggested (presence of spacers sp37-38, ST539) [32], instead of ST641 in SpolDB3. M. caprae and 2 sub lineages of $M$. pinipedii, a new member of MTC [33], were added. Within the M. africanum subspecies, more is known today on its taxonomical status, thanks to improvement of spoligotyping through the 68 spacers format and thanks to the discovery of other lineage-specific genetic markers [34,35]. Using a dedicated software (structure version $2,[36,37])$ to infer the population structure of the $M$. africanum spoligotyping dataset of SpolDB4, one would suggest the existence of at least 4 populations in SpolDB4 (results not shown), however more data on the genetic diversity of $M$. africanum will be required to be able to get a clearer picture of the global population structure of this pathogen.

\section{New genetic lineages within $M$. tuberculosis stricto sensu}

Among M. tuberculosis stricto sensu, new visual rules defining 22 lineages/sub lineages are described. The previously defined Central-Asian (CAS) lineage was split into CAS1-Delhi type (ST26) found mainly in India and in the Indian subcontinent [38,39], and CAS1-Kilimanjaro (ST21) found in Tanzania [40]. Within the East-AfricanIndian (EAI) lineage, new prototypic spoligotyping-signatures for 4 sub lineages are presented (EAI2-Nonthaburi, EAI6-Bangladesh/1, EAI7-Bangladesh/2 and EAI8-Madagascar). Douglas et al. designated the EAI2 clade as the "Manila family" [41]. We further linked the Nonthaburi group of strains from Thailand [42] to this lineage (results not shown). EAI3 and EAI4, are now being shown as phylogeographically specific from India and Vietnam respectively, with suggested designations of EAI3-IND and EAI4VNM. Two new lineages from Bangladesh are found, designated as EAI6-Bangladesh/1 (58.1\% of isolates from Bangladesh) and EAI7-Bangladesh/2 (91.2\% of isolates from Bangladesh). EAI6-BGD1 harbours specificity for the eastern part of the South Asian region since it is also found in neighbouring Myanmar (results not shown).

Within the Haarlem ( $\mathrm{H})$ lineage, a 4 th sub lineage $(\mathrm{H} 4)$ is tentatively added. It is characterized by the absence of spacers 29-31 and 33-36 (prototypes ST127 and/or ST777). More than $60 \%$ of ST127 isolates are localized in Armenia, Austria, Finland, Georgia, Iran, and Russia. A likely related pattern (ST777) is found in Saudi Arabia. An hypothesis is that these strains could represent an intermediate genetic link between the previously defined Haarlem-1 (H1, ST 47) and Haarlem-3 (H3, ST50) genotypes. Type ST777, which shows a single spacer difference from ST 127 , is also found in Kazakhstan, Russia, and Georgia $(n=26)$. These isolates are likely to be identical to the recently described "Ural" family of strains [43]. They suggest the prominent role of Central Asia as a hub of migratory routes of Homo sapiens sapiens and its role in the history of infectious diseases.

Within the Latin-American-Mediterranean (LAM) lineage, we rebaptised the LAM7 sub lineage as LAM7-Turkey since recent results suggested that ST41 is predominant in Asia Minor [44]. Similarly, the LAM10 sub lineage was renamed as LAM10-Cameroun $[45,46]$. Two sub lineages are new, LAM11-ZWE (ST 59) with $57.8 \%$ of isolates originating from Zimbabwe [47], and LAM12-Madrid1 (ST209) [48]. The LAM11-ZWE is likely to be identical to the recently described Meru family found in Tanzania [40]. The "Manu" family, a new family from India, which could be an ancestral clone of principal genetic group 1 strains [39], is tentatively sub-divided into Manu1 (deletion of spacer 34), Manu2 (deletion of spacers 33-34), and Manu3 (deletion of spacers 34-36). The central role of India, and more generally of Asia in tuberculosis evolutionary history is more and more evident. The $\mathrm{S}$ lineage which is highly prevalent in Sicily and Sardinia, could be identical to the F28 clade in South Africa [30,49]; the existence of this genotype family was confirmed in SpolDB4, however its origin remains unknown. The "T" families (modern TB strains) stayed ill-defined with more than 600 unclassified STs. They were stratified into 5 subclades (T1-T5) based on single-spacer differences. 8 nested clades, with robust spoligotyping-signatures were extracted; with the exception of "Tuscany", their names were built using their proximate upper-clade designation (T1 to T5), followed by their presumed geographical specificity: T3-Ethiopia (ST149); T5-Russia/1 (ST254), T1Russia/2 (ST280), T3-Osaka (ST627), T5-Madrid/2 (ST58), T4-Central Europe/1 (ST39), T2-Uganda (ST135), and "Tuscany" (ST1737). ST149 was previously shown to be frequent in Ethiopia and in Denmark among Ethiopian immigrants. This low-banding IS6110 clone had been identified based on IS6110-RFLP as early as 1995 and represented $36.2 \%$ of isolates from this country [50]. ST254 and ST280 were repeatedly isolated from clinical isolates in Russia, in former Russian soviet republics and in Northern and Eastern European countries (Estonia, Finland, Georgia, Latvia, Poland, Russia). ST1737, with a single spacer difference from ST254, was recently found in Italy and designated as "Tuscany" [51]. ST627 was identified for the first time in Finland and repeatedly found in the Okayama district and elsewhere in Japan [52]. T5-Madrid/ 
2 isolates were previously found to be characteristic of Spanish-related settings [48]. T2-Uganda, which was first described by Niemann et al., was repeatedly found in East Africa, and at least 7 STs with a prototypic signature are linked to East-Africa. Last but not least, the T4-CE1 (for Central-Europe/1) was tentatively identified based on similarity between ST39 found in Europe and South Africa, and some likely derived genotypes found both in South and North America (ST94, ST430, ST1258). Among those, ST1258 represents the most prevalent spoligotype detected by the Inuit's community in Nunavik, Canada. Whether this type has been introduced by a casual European contact into this community, or has been endemic among the Inuits is currently under investigation [53].

The X genotype family (X1-X3 sub lineages) was initially described thanks to data-mining [27]. This family is today a well-characterized IS6110 low-banding family, duly characterized by IS6110-RFLP as well as by high-throughput genetic methods [54-57]; it is prevalent in UK, in USA and in former British colonies. Lastly, a Vietnamese genotype family characterized by the absence of IS6110 insertion elements, was shown to bear a specific spoligotyping signature which is characterized by the deletion of spacers 19-41 (ST 405), and was designated as the "Zero copy" clade [58].

\section{Comparison between the supervised and an unsupervised Naive Bayes statistical approach of classification of spoligotypes}

Data-mining and clustering techniques are the focus of intense research in Information and Bio Sciences [59]. Classification of spoligotypes, given the almost infinite dimension of theoretical allelic number $-n=2^{43}$ in the current format that does not detect the complete set of known spacers-, is not a trivial task. A recent attempt to use a statistical approach of classification of spoligotypes through the utilization of a Naïve Bayes algorithm and a mixture model was suggested [60]. A good correlation was found between the two techniques for a large number of genotype families defined, with strong support of the stability value. However, the mixture model also suggested the existence of new spoligotype signatures and a total of 48 families ( $\mathrm{N} 1$ to $\mathrm{N} 48$ ) [60]. Some of these signatures are confirmed by this study, others are not. A similar approach using a Markov model is currently under development in our laboratory.

\section{Unclassified spoligotypes}

454 STs (23.4\%) did not correspond to any pattern recognition rule when data were mined automatically using SpolNet. Nonetheless, we attributed a family label to these spoligotypes too by extending the rules defined initially, and subsequently by a visual assessment on each unclassified ST. Thus, 314 more STs were tentatively classified with a family label, and only 131 STs (7\% of the total) remained unclassified. These STs harboured patterns with either important blocks of deletion, disseminated deletions, mixed signatures, or patterns, which at this time did not correspond to any known spoligotypesignatures.

\section{Results \\ Population genetics}

The worldwide distribution of data points was assessed within eight regions. Isolates from Europe and North America represented $65.5 \%$ of all entries. Africa, Far-East Asia, Middle East and Central Asia, and South America were equally represented (6.5\% to $8.3 \%$ of entries) whereas Central America and Oceania were underrepresented $(3.6 \%$ and $1.1 \%$ of entries). The overrepresentation of M. bovis from Europe and South America (about 30 and $25 \%$ respectively) limits the interpretation on global M. bovis genetic diversity, but also reflects the reality of the importance of beef cattle economy in South America (Brazil and Argentina) and Europe. Orphan spoligotypes, represented $35.7 \%$ and $16.9 \%$ of the isolates in Europe and North America respectively, and ranged from $1.2 \%$ to $11.5 \%$ in the other regions.

Figure 2 is a synthetic histogram of the distribution of 10 main lineages in the studied continents. In brief, Beijing and Beijing-like strains represent about $50 \%$ of the strains in Far East-Asia and 13\% of isolates globally. In Europe, the Haarlem lineage represents about $25 \%$ of the isolates. In South America, about $50 \%$ of the strains belong to the LAM family. Three major genotypic families (Haarlem, LAM, and T) are the most frequent in Africa, Central America, Europe and South America. Outside Europe, The Haarlem strains were mainly found in Central America and Caribbean (about 25\%), suggesting a link of Haarlem to the post-Columbus European colonization [61] (Figure $3)$. The presence of the LAM family is highest in Venezuela (65\%) [62], in the Mediterranean basin (e.g. 34\% in Algeria, $55 \%$ in Morocco, $30 \%$ in Spain), and in the Caribbean region (30\% in Cuba and Haiti, $17.4 \%$ in French Guiana, $15 \%$ in French Caribbean islands) (Figure 3A). The "illdefined" T genetic family, was found in all continents, and corresponded to about $30 \%$ of all entries in the database. Undoubtedly, MLVA and/or SNPs data will improve the knowledge of the identity of these isolates designated as "T" by default [26].

The Beijing family of strains is prevalent in Far-East-Asia, but also in Middle-East-Central Asia and Oceania (45.9\%, $16.5 \%$ and $17.2 \%$ respectively) (Figure 3 ). The Beijing genotype which may have been endemic in China for a long time [63] is emerging in some parts of the world, especially in countries of the former Soviet Union, and to a lesser extent in the Western world [64]. The East-AfricanIndian (EAI) family is also highly prevalent in these areas 


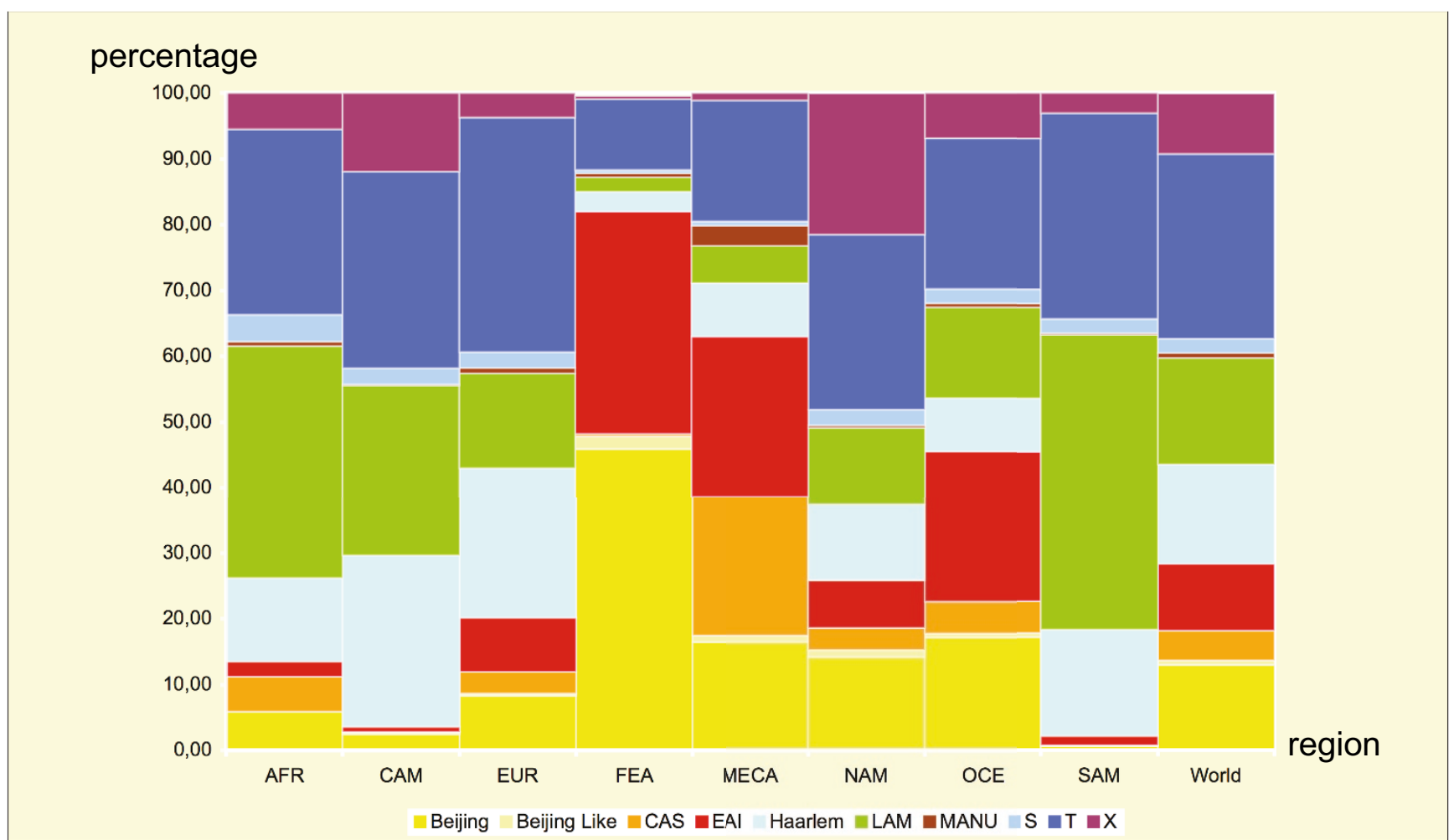

Abbreviations $\mathrm{AFR}=$ Africa, $\mathrm{CAM}=\mathrm{C}$ entral America, $\mathrm{EUR}=$ Europe, $\mathrm{FEA}=$ Far-East Asia, $\mathrm{MECA}=\mathrm{Middle}-\mathrm{East}$ and $\mathrm{C}$ entral Asia, NAM = North America, OCE = Oceania, SAM = South America

\section{Figure 2}

Percentage of main spoligotyping-defined MTC genotype families within SpolDB4 (Beijing, Beijing-like, CAS, EAI, Haarlem, LAM, Manu, $X, T$ ), by studied continents and worldwide. Abbreviations : AFR = Africa, CAM = Central America, EUR = Europe, FEA = Far-East Asia, MECA = Middle-East and Central Asia, NAM = North America, OCE = Oceania, SAM = South America.

(33.8\% in Far-East-Asia, 24.3\% in the Middle East and Central Asia, and 22.9\% in Oceania). The EAI lineage is more prevalent in South-East Asia, particularly in the Philippines (73\%; [41]), in Myanmar and Malaysia (53\% ; $[65])$, in Vietnam and Thailand (32\%; [62]) (Figure 3).

The CAS1-Delhi family is essentially localized in the Middle-East and Central Asia, more specifically in South-Asia, $(21.2 \%)$, and preferentially in India $(75 \% ;[38,66])$. It is also found in other countries of this region such as Iran, and Pakistan $[67,68]$. It has also been found in several others regions (Africa, 5.3\%; Central America, 0.1\%; Europe, 3.3\%; Far-East-Asia, 0.4\%; North-America, 3.3\%; Oceania, 4.8\%). In Europe and Australia, these strains were frequently found to be linked with immigrants from South Asia [24].

Lastly, the X family is highly prevalent in North America (21.5\%) and Central American (11.9\%) regions. It could be linked to an Anglo-Saxon ancestry, as it has been encountered in English-colonized areas such as in the
United Kingdom, United States, Australia, South Africa and in the Caribbean [27]. However, according to other investigators, this group of strains is currently correlated with African-Americans, a fact however that may not represent the ancestry of this genotype [69]. More studies should be done to clarify this issue.

Analysis of the spreading and epidemiological status of MTC clones We further analyzed the epidemic status of each spoligotyping-defined clone as shown by the index C1 and C2 [26] as well as the inter-continental match between STs. Results are shown in Table 1 and Table 2. Briefly, the Spreading Index (SI) represents a mean number of occurrences of a clone, independent of the setting. Fourteen types were defined as "epidemic" (SI>25), 65 as "common" $(10<\mathrm{SI}<25), 669$ as "recurrent" $(\mathrm{SI}<10)$ and 1090 as "rare" $(\mathrm{SI} \leq 2)$. The Table 1 shows the results based on combination of $\mathrm{C} 1$ and $\mathrm{C} 2$ which provides 12 classes ranging from the highly localized (endemic) and numerous (epidemic), to the highly spread (ubiquitous) and infrequent (rare) genotypes. When analyzed geographi- 
Table I: A. Definition of the variables (MC, Ar, SI) used in SpoIDB4 to define : (I) the geographic index CI (Endemic, Localized, Ubiquitous) (2) the quantitative index C2 (Epidemic, Common, Recurrent, Rare). B. Distribution of the 1939 Shared-types in 12 classes.

\begin{tabular}{|c|c|c|c|}
\hline Name & Abbreviation & Type of data, Def. & Rules for Definition of Qualifiers ( $\mathrm{Cl}$ and $\mathrm{C} 2$ ) \\
\hline \multicolumn{4}{|l|}{ A Definitions } \\
\hline Matching Code & MC & I-8 digits, built by linking region codes & $\begin{array}{l}\text { If I digit, then } \mathrm{Cl}=\text { Endemic (genotype found in one } \\
\text { macroregion only) } \\
\text { If } 2 \text { digits, then } \mathrm{Cl}=\text { Localized (genotype found in two } \\
\text { macroregions) } \\
\text { If } \geq 3 \text { digits, go to Area section below for further } \\
\text { interpretation }\end{array}$ \\
\hline Area & $\operatorname{Ar}$ & $\begin{array}{l}\text { numeric, } n^{\circ} \text { of countries in which a given } \\
\text { SIT is found }\end{array}$ & $\begin{array}{l}\text { If } M C \geq 3 \text { digits and Areas } \leq 5 ; \mathrm{Cl}=\text { Localized } \\
\text { If } M C \geq 3 \text { digits and Areas } \geq 6 ; \mathrm{Cl}=\text { Ubiquitous (genotype } \\
\text { found in more than three macroregions) }\end{array}$ \\
\hline Spreading Index & SI & $\begin{array}{l}\text { numeric, mean indicator of spreading } \\
\text { independent of geography } \mathrm{SI}=\mathrm{n} / \mathrm{Ar} \\
\text { where } \mathrm{n} \text { is the absolute value for a given } \\
\text { shared-type }\end{array}$ & $\begin{array}{l}\text { If } \mathrm{SI} \geq 25 ; \mathrm{C} 2=\text { Epidemic } \\
\text { If } \mathrm{I} 0<\mathrm{SI}<24 ; \mathrm{C} 2=\text { Common } \\
\text { If } 3<\mathrm{SI}<9 ; \mathrm{C} 2=\text { Recurrent } \\
\text { If } \mathrm{SI} \leq 2 ; \mathrm{C} 2=\text { Rare }\end{array}$ \\
\hline \multicolumn{4}{|c|}{ B Distribution of the 1939 genotypes in 12 class } \\
\hline Endemic Epidemic & 6 & Endemic Recurrent & 286 \\
\hline Localized Epidemic & 2 & Localized Recurrent & 207 \\
\hline Ubiquitous Epidemic & 6 & Ubiquitous Recurrent & 176 \\
\hline Endemic Common & 31 & Endemic Rare & 501 \\
\hline Localized Common & 14 & Localized Rare & 587 \\
\hline $\begin{array}{l}\text { Ubiquitous } \\
\text { Common }\end{array}$ & 20 & Ubiquitous Rare & 82 \\
\hline $\mathrm{NA}^{*}$ & 21 & Total & 1939 \\
\hline *not applicable & & & \\
\hline
\end{tabular}

cally using the Matching Code (MC), a total of 824 types are found within a single macro region ("Endemic", $42,5 \%)$, and 564 types are present in exactly two settings ("localized", 29\%). Types present in three macro regions but found in five or less areas are also defined as localized and totalled 246 types. The Intercontinental match of these types was not analyzed further. All other types, being present in at least three continents and in at least six areas, or present in four or more continents, $(n=551)$, were declared as "ubiquitous". The Table 2 shows the number of endemic types per continent and presents the matching results between "localized" types. Endemic types are likely to represent local clones, current end points of evolution, either because of extinction (for ancient clones) or because epidemiological transmission was not yet followed by mutation for emerging ones. Independently of recruitment, the number of endemic types is minimal in Oceania and Central America (0.005 endemic type/occurrence), two regions that have experienced a negative migratory balance for centuries. In all other continents, with a 0.015 to 0.03 endemic type/occurrence, and slightly more in Middle-East and Central Asia (0.037), rates of endemism appear to be similar, a feature resulting from a combination of the intrinsic molecular clock of the DR locus, the age of the tubercle bacilli, and the historical tuberculosis transmission waves.
Toward an interactive system of geographic atlas of genotype frequency data of Mycobacterium tuberculosis

Figure 3 and 4 illustrate a mixed representation (by absolute case number and by frequency) of the distribution of the most frequent STs shown in Figure 1, and grouped by genetic lineage, for the following six MTC lineages: Beijing, M. bovis, Central-Asia, East-African-Indian, Haarlem and Latin-American-Mediterranean. These Figures provides the best display of the global phylogeographical structure of the MTC population. Similar results focused in Europe (data not shown) and using SpolDB4 suggests the existence of fine geographic genetic clines between four prevalent genotypes belonging to the modern MTC types, i.e. ST53-T1, ST50-Haarlem3, ST47-Haarlem1, ST42-LAM9 [70].

\section{Discussion}

In this study, we data-mined an updated international spoligotype database of the M. tuberculosis complex, SpolDB4, both for improving classification of MTC genomes, and for presenting a more reliable snapshot picture of the global and local population genetics of tubercle bacilli. Considering the known diversity of the origin of patients, SpolDB4 represents clinical isolates from a total of 141 countries. This is to our knowledge the largest collaborative effort to describe the worldwide genetic structure of MTC. 
Table 2: Analysis of the geographical Inter and Intra-continental matches between the shared-types found within I or 2 settings (endemic types $n=824)$ and localized types $(n=564)$, within and between the 8 macro-regions. The geographical analysis of the matches between localized types found in 3 macroregions and 5 settings or more $(n=246)$ and between the ubiquitous types (found in more than 3 regions $(n=284)$ was not done. Number of intra and intercontinental matches between STs detected between the 8 macro regions previously defined.

\begin{tabular}{|c|c|c|c|c|c|c|c|c|}
\hline \multirow[t]{2}{*}{ Macroregion (code) } & \multirow[t]{2}{*}{ Africa } & \multicolumn{3}{|c|}{ Americas } & \multirow[t]{2}{*}{ Europe } & \multicolumn{2}{|l|}{ Asia } & \multirow[t]{2}{*}{ Oceania } \\
\hline & & $\begin{array}{l}\text { North } \\
\text { America }\end{array}$ & $\begin{array}{c}\text { Central America/ } \\
\text { Caribbean }\end{array}$ & $\begin{array}{l}\text { South } \\
\text { America }\end{array}$ & & $\begin{array}{l}\text { Middle-East and } \\
\text { Central-Asia }\end{array}$ & $\begin{array}{c}\text { Far-East } \\
\text { Asia }\end{array}$ & \\
\hline Africa (I) & 73 & 29 & 2 & 7 & 79 & 7 & 3 & 0 \\
\hline North America (2) & & 138 & 8 & 35 & 131 & 34 & 45 & 4 \\
\hline Central America (3) & & & 7 & 0 & 9 & 1 & 2 & 0 \\
\hline South America (4) & & & & 94 & 69 & ND & 0 & 3 \\
\hline Europe (5) & & & & & 351 & 56 & 25 & 3 \\
\hline Middle-East Asia (6) & & & & & & 99 & 8 & 0 \\
\hline Far-East Asia (7) & & & & & & & 61 & 4 \\
\hline Oceania (8) & & & & & & & & 1 \\
\hline
\end{tabular}

$N D=$ not done

The scaling-up that represents SpolDB4 relatively to SpolDB3 $(4 \times)$, allowed new sub lineages to be discovered. However, it also showed the limit of the approach of using spoligotyping only to define the precise identity of a given MTC clone, since over fitting was observed. Combined DR, MLVA, SNPs, Region of Differences polymorphic datasets are now required to improve our knowledge of MTC genomes diversity.

Today's observed pattern of phylogeographical diversity of MTC is undoubtedly the result of both a deep ecological differentiation and of a more recent demographic and epidemic history. It is tempting to speculate, especially since the publication of the recent studies done on M. canettii $[15,71]$, that TB is as old as humanity. It is also tempting to hypothesize that the EAI ancestral strains spread back from Asia to Africa through India concomitantly to human migrations [72], and that evolution gave rise to the CAS lineage, and possibly to all "modern" TB lineages. Recently, Mokrousov et al. used the Beijing lineage as a model to compare its phylogeography with human demography and Y chromosome-based phylogeography [73]. Further work using other genetic markers will help to better define the retrospective demographical history of the various sub lineages described here.

Such an endeavour as the building of SpolDB4, and more generally the building of a representative genetic diversity database, should however assume limitations concerning both the quality and representativity of data. We partially eliminated the first problems by carefully double checking many datasets visually, reinterpreting other datasets by asking for the autoradiography results sent as electronic files, or by simply excluding datasets harbouring systematic genotyping errors. The procedure of examining only STs improves data quality by minimizing artefacts analysis. Some internationally agreed upon recommendations to improve the quality of spoligotyping are also in progress and will be published elsewhere. The second problem (representativity) is more chronic and difficult to solve. More financial means should be devoted to improving both mycobacteriology diagnostic and genotyping facilities in countries where the outbreaks prevail. Another limitation using spoligotyping is the study of mixed populations of bacilli [74]. Indeed, MLVA is appropriate, contrary to spoligotyping, to reveal the existence of dual infections, an issue which, especially in high prevalence countries, was probably underestimated and that may sometimes jeopardize spoligotyping results. Future studies should attempt to evaluate whether admixture models can in fact explain some yet undefined mixed spoligotyping signatures.

One of the major lessons from this collaborative effort is that new markers such as MLVA, SNPs or others are needed to improve our knowledge on the population structure of MTC. MLVA provides an improved knowledge of MTC clonal complexes, a strategy for the MTC which could even be more effective than the Multi-LocusSequence-Typing (MLST) approach $[55,75]$. MLVA allows the investigator to limit the quantity of required genotyping to only type epidemiologically or phylogenetically informative markers, depending on the branch depth (regarding time) to which a given data set should to be analyzed [76]. Rapid changes in MTC genotyping methodologies have lead to numerous ongoing debates about the choice of the best genotyping strategy [77-79].

Our efforts to characterize the classification of the tuberculosis strains present within populations have also led to 

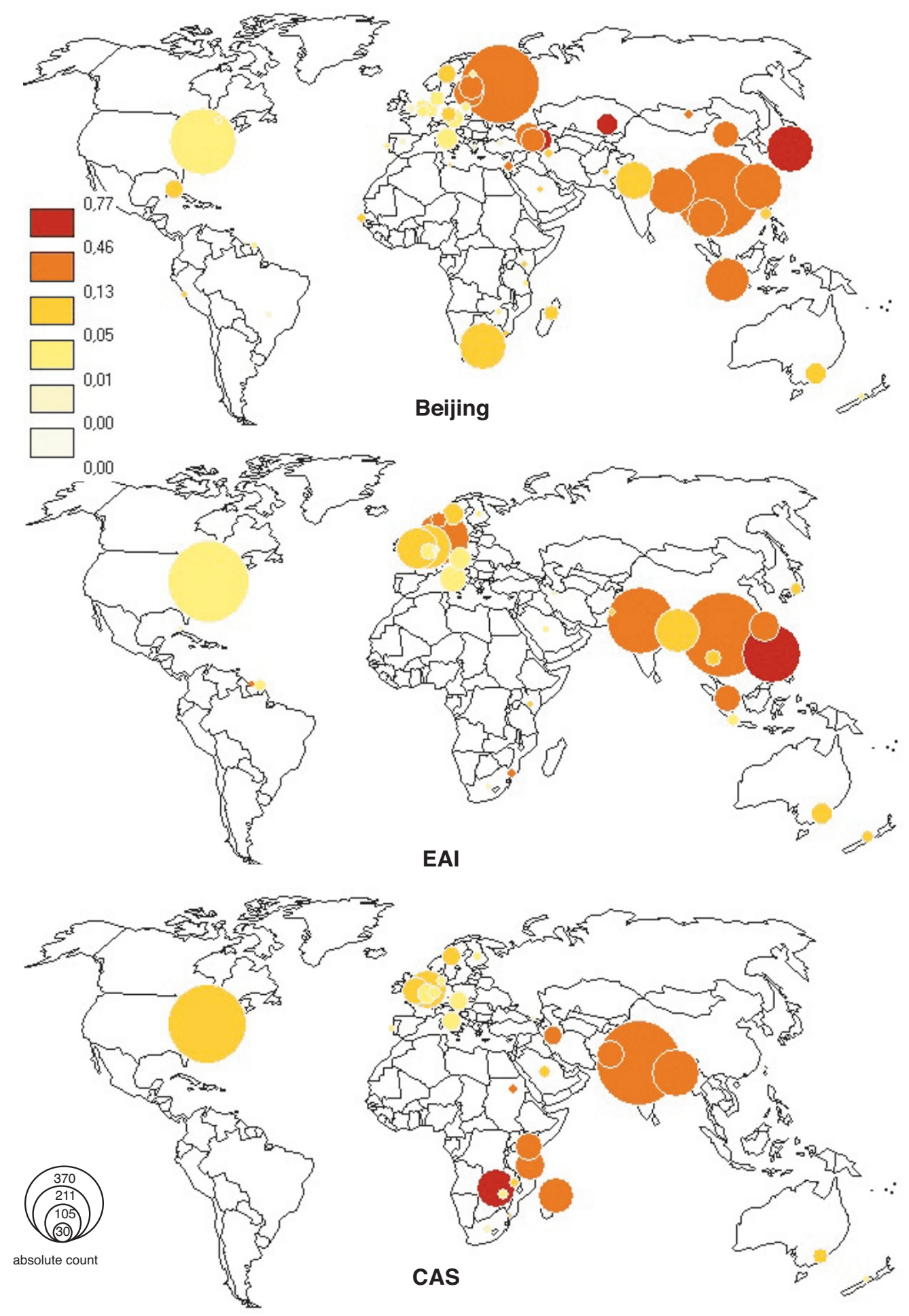

Figure 3

Synthesizing World Maps showing absolute (diameter) and percentage (colour) numbers of 3 genotype families within each country: Beijing; EAI (East-African Indian) CAS (Central Asia). These maps were built on an updated SpolDB4 on 2005 September $14^{\text {th }}$, on clusters of the 50 most frequent shared types as shown in Table I, for a total of $n=I 7212$ isolates (Beijing $n=$ 4042, $\mathrm{EAI} n=1684$, CAS $\mathrm{n}=1022$ ). 

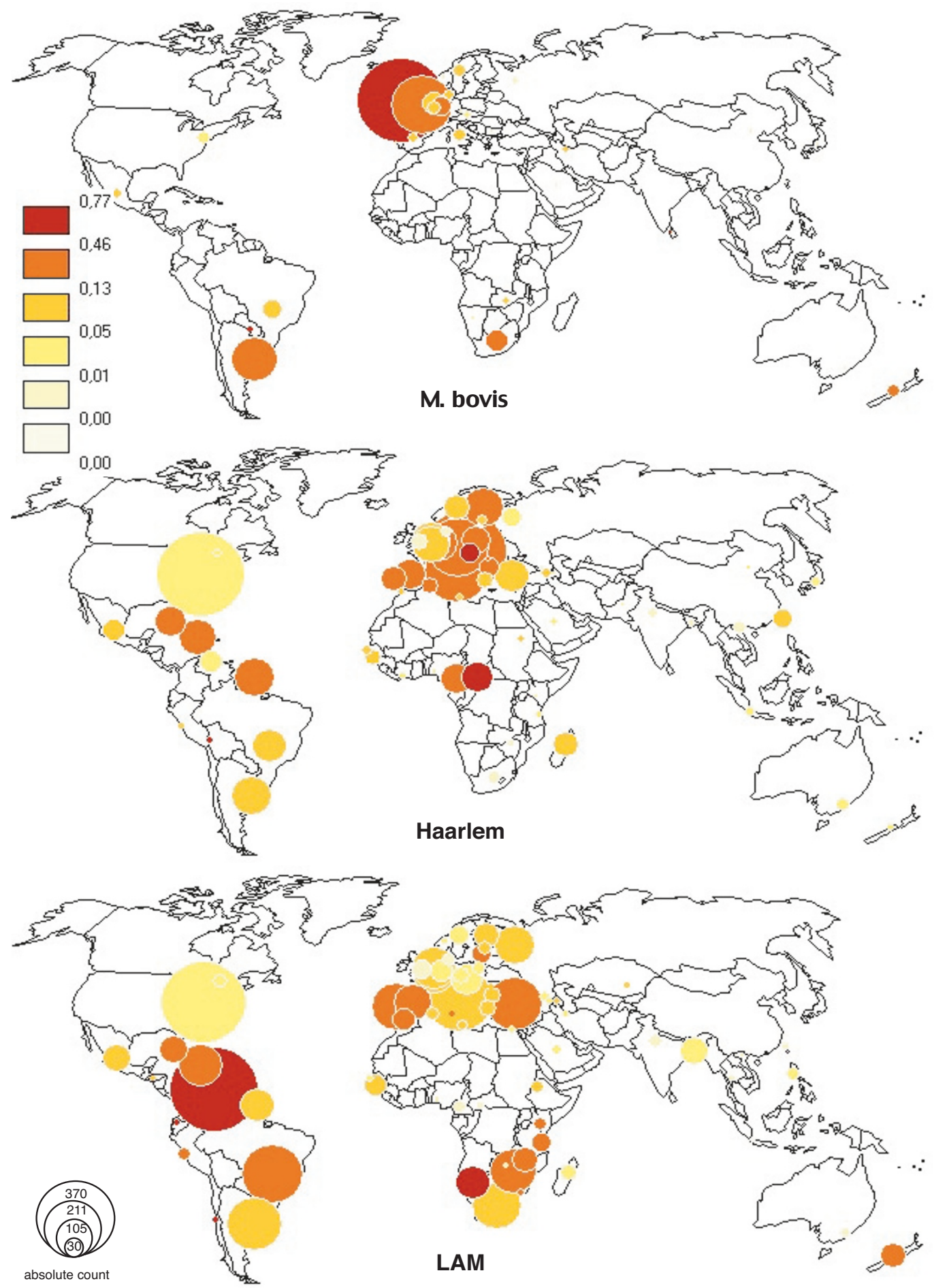

\section{Figure 4}

Synthesizing World Maps showing absolute (diameter) and percentage (colour) numbers of 3 genotype families within each country: M. bovis; Haarlem; Latin-American and Mediterranean (LAM). These maps were built on an updated SpolDB4 on 2005 September $14^{\text {th }}$, on clusters of the 50 most frequent shared types as shown in figure I, for a total of $n=I 72 I 2$ isolates $(M$. bovis $n=3888$, LAM $n=3400$, Haarlem $n=3176$ ). Maps were built using Philcarto (P. Waniez, version 4.38). 
an increased understanding of their global distribution. Our results do not fully agree with recently published results [11] suggesting that $M$. tuberculosis did not possess a finer geographic structure than the one defined within broad regions (East Asia, Africa, Europe, Philippines and Americas). On the contrary, our results demonstrate that the genetic diversity of $M$. tuberculosis genomes and hence their population structure, is strongly linked to geography at a fine geographical scale, thus reinforcing the importance of localized effort to control tuberculosis and to consider the global tuberculosis pandemia as the sum of very different and genetically separate individual outbreaks. Future work should focus on an adequate modelization of the database according to demography and tuberculosis prevalence, to present a more realistic quantitative TB genetic landscape.

Linking these results for a clinical benefit for individual patients remains another challenge. In particular, we need to better understand why in certain areas a small number of strains are causing a disproportionate number of cases of the disease and we need to better understand the effects of host's genetic and environmental variability on the presentation of the disease [80]. In the Western world TB occurs mainly due to reactivation of disease in the older age class and immigration in younger ones. Consequently the characteristics of the bacterial population are those of an old outbreak under extinction, with the superimposition of new characteristics due to cases of importation and recent transmission. The more homogeneous population structure in high-burden countries is more likely to reflect the ongoing transmission in all age classes. Selection of particular genotypes (e.g. due to vaccination with M. bovis BCG) and clonal selection [81] has also been suggested $[50,82]$. Previous colonization histories, and of course more deeply rooted anthropological structures as well as geographic isolation, may have also contributed to the complex tuberculosis genetic landscape.

\section{Conclusion}

The SpolDB4 database is by far one of the largest publicly available database on $M$. tuberculosis complex genetic polymorphism with a universal nomenclature system of spoligotyping (octal or arbitrary ST number) as well as a global epidemiological information system. Our results suggest the existence of fine geographical genetic clines that may correlate to the passed Homo sapiens sapiens demographical history. Further combined (multimarkers) genetic databases, as well as local finer scale analysis are in progress to further analyze the complexity of the evolutionary history of the MTC.

\section{Methods \\ Database}

A total of 39,295 entries were collected in an Access ${ }^{\circledast}$ database. The Previous STs numbered 1 to 817 were previously described in SpolDB3. ST633, 714, 729, 770, 797, which were missing in the former version were replaced by new genotypes. SpolDB4 is available [see additional file 1] and can also be downloaded (sorted/unsorted versions) at: [83]. A dedicated interactive website version is available [93].

The distribution by continent and country of isolation is shown below. Macro region name, defining acronym, identification number and total number of patterns (into brackets) are respectively: Africa AFR -1 ( $\mathrm{n}=3121)$, Central-America CAM -2 $(\mathrm{n}=1353)$, Europe EUR $-3(\mathrm{n}=$ 13624), Far-East Asia FEA -4 $(\mathrm{n}=2624)$, Middle East and Central Asia MECA -5 ( $\mathrm{n}=2639)$, North-America NAM -6 $(\mathrm{n}=9153)$, Oceania OCE $-7(\mathrm{n}=235)$, South-America SAM -8 $(\mathrm{n}=3176)$.

\section{Origin of spoligotypes}

The spoligotypes were either obtained at the Pasteur Institute of Guadeloupe using the 43-spacers format and home-made membranes $[84,85]$, received from co-investigators and collaborating laboratories, or retrieved from local molecular epidemiological studies or diversitydriven published articles. The sampling is still far from being representative for all countries, and in many cases, limited epidemiological and patient information on the isolates were available. However, we assume that this " convenience sample " is representative of world-wide TB genotypes and that, with spoligotypes from almost $40.000 \mathrm{M}$. tuberculosis isolates, this $4^{\text {th }}$ version allows for new and robust inferences in phylogeography, population genetics, and global epidemiology of $M$. tuberculosis to be drawn.

\section{Description}

The description of SpolDB4, per country of isolation of the clinical isolates, or in very rare cases, by country of origin of the patients, is as follows.

AFR, $(\mathrm{n}=3121)$ : Angola $(\mathrm{n}=4)$, Burundi $(\mathrm{n}=18)$, Benin $(n=4)$, Botswana $(n=1)$, Burkina Faso $(n=1)$, Centrafrican republic $(n=154)$, Ivory Coast $(n=84)$, Cameroon $(\mathrm{n}=498)$, Congo Democratic (former Zaire) $(\mathrm{n}=7)$, Congo $(n=20)$, Djibouti $(n=5)$, Algeria $(n=137)$, Egypt $(n=60)$, Eritrea $(n=8)$, Ethiopia $(n=153)$, Gabon $(n=$ $2)$, Ghana $(\mathrm{n}=1)$, Guinea $(\mathrm{n}=7)$, Gambia $(\mathrm{n}=1)$, Guinea-Bissau $(n=217)$, Kenya $(n=71)$, Libya $(n=54)$, Morocco $(\mathrm{n}=127)$, Mali $(\mathrm{n}=5)$, Mozambique $(\mathrm{n}=28)$, Mauritania $(n=4)$, Malawi $(n=122)$, Namibia $(n=79)$, Niger $(n=1)$, Nigeria $(n=6)$, Rwanda $(n=8)$, Sudan ( $=41)$, Senegal $(n=69)$, Sierra Leone $(n=3)$, Somalia ( 
=226), Tunisia $(\mathrm{n}=10)$, Tanzania $(\mathrm{n}=9)$, Uganda $(\mathrm{n}=$ $11)$, South Africa $(n=564)$, Zambia $(n=43)$, Zimbabwe $(\mathrm{n}=247)$, East-Africa (not specified, $\mathrm{n}=15)$.

CAM, ( $\mathrm{n}=1353)$ : Netherlands Antilles $(\mathrm{n}=1)$, Barbados $(\mathrm{n}=6)$, Costa Rica $(\mathrm{n}=1)$ Cuba $(\mathrm{n}=239)$, Commonwealth of Dominica $(n=1)$, Guadeloupe $(n=232)$, Honduras $(\mathrm{n}=7)$, Haiti $(\mathrm{n}=375)$, Mexico $(\mathrm{n}=386)$, Martinique $(\mathrm{n}=105)$.

EUR, ( $\mathrm{n}=13624)$ : Albania $(\mathrm{n}=5)$, Austria $(\mathrm{n}=1456)$, Belgium $(\mathrm{n}=517)$, Bulgaria $(\mathrm{n}=2)$, Bosnia and Herzegovina $(\mathrm{n}=3)$, Czech Republic $(\mathrm{n}=393)$, Germany $(\mathrm{n}=$ 574), Denmark $(\mathrm{n}=281)$, Spain $(\mathrm{n}=374)$, Estonia $(\mathrm{n}=$ $115)$, Finland $(n=347)$, France $(n=2265)$, United-Kingdom $(n=1523)$, Greece $(n=1)$, Hungary $(n=62)$, Ireland ( $\mathrm{n}=1559^{*}$, mainly M. bovis), Italy $(\mathrm{n}=934)$, Sicily $(\mathrm{n}=$ 125), Latvia $(\mathrm{n}=138)$, Liechtenstein $(\mathrm{n}=1)$, Lithuania ( $\mathrm{n}$ $=3)$, Luxembourg $(\mathrm{n}=1)$, Moldova $(\mathrm{n}=1)$, Macedonia $(\mathrm{n}$ $=7)$, Netherlands $(\mathrm{n}=973)$, Norway $(\mathrm{n}=31)$, Poland $(\mathrm{n}$ =227), Portugal $(n=336)$, Romania $(n=26)$, Russia $(n=$ $986)$, Sweden $(n=328)$, Swiss $(n=1)$, Ukraine $(n=4)$, Yugoslavia $(\mathrm{n}=28)$.

FEA, $(\mathrm{n}=2624)$ : China $(\mathrm{n}=145)$, Indonesia $(\mathrm{n}=344)$, Japan $(n=138)$, Korea $(n=4)$, Myanmar $(n=20)$, Mongolia $(n=19)$, Malaysia $(n=598)$, Philippines $(n=237)$, Singapore $(n=4)$, Thailand $(n=302)$, Vietnam $(n=789)$, Far-east-Asia unspecified $(\mathrm{n}=24)$.

MECA, ( $\mathrm{n}=2639)$ : Afghanistan $(\mathrm{n}=3)$, Armenia $(\mathrm{n}=$ 119) Azerbaijan $(n=71)$, Bangladesh $(n=676)$, Comoro Islands $(n=14)$, Georgia $(n=272)$, India $(n=483)$, Iran $(\mathrm{n}=110)$, Iraq $(\mathrm{n}=5)$, Israel $(\mathrm{n}=15)$, Kazakhstan $(\mathrm{n}=$ $55)$, Lebanon $(n=2)$, Sri Lanka $(n=16)$, Madagascar $(n=$ 395), Mauritius $(n=21)$, Nepal $(n=6)$, Pakistan $(n=90)$, Reunion Island $(\mathrm{n}=16)$, Saudi Arabia $(\mathrm{n}=99)$, Turkey $(\mathrm{n}$ $=170)$, Yemen $(n=1)$.

NAM, $(n=9153)$ : Canada $(n=266)$, Greenland $(n=4)$, USA unspecified ( $\mathrm{n}=1690$ ), USA (Alabama, $\mathrm{n}=3$ ), USA (New-York, $\mathrm{n}=5948$ ), USA (Texas, $\mathrm{n}=1242$ ).

OCE, $(\mathrm{n}=235)$ : Australia $(\mathrm{n}=36)$, New Zealand $(\mathrm{n}=$ $151)$, French Polynesia $(n=2)$, USA (Hawaii, $n=46)$.

SAM, $(\mathrm{n}=3176)$ : Argentina $(\mathrm{n}=1150 *$, mainly M. bovis $)$, Bolivia $(\mathrm{n}=4)$, Brazil $(\mathrm{n}=842)$, Chile $(\mathrm{n}=2)$, Colombia $(\mathrm{n}=1)$, Ecuador $(\mathrm{n}=12)$, French Guiana $(\mathrm{n}=375)$, Guiana $(n=3)$, Peru $(n=96)$, Paraguay $(n=6)$, Suriname $(n=8)$, Uruguay $(n=5)$, Venezuela $(n=672)$.

\section{Data format}

All spoligotypes were converted into the octal format within Excel spreadsheets [86]. The database is main- tained under an Access ${ }^{\circledast}$ format, whereas a Bionumerics ${ }^{\circledast}$ version is also regularly updated (Applied Maths, SintMarteen-Latem, Belgium). An updated mySQL-Java-based version is in development. The Information system automatically attributes the shared-type (ST) number to all the entries that correspond to an identical spoligotype found in two or more individual patient isolates, whereas, the entries occurring only once are considered as orphan.

\section{Combined automatized-expert based classification of spoligotypes}

To be classified by SpolNet, spoligotypes must be expressed under the form of binary vectors of 43 bits. Using clade and Principal Genetic Groups (PGG) clustering [87], which was previously established or collected by our laboratory and others [88], computerized rules have been generated to sort spoligotypes into clades. Each computerized rule is a translation of a global visual recognition rule. This rule may be defined using a combination of four criteria: (a) presence of a block of one or many consecutive bits (b) absence of a block of one or many consecutive bits (c) presence of at least one bit in a given bit interval (d) absence of at least one bit in a given bit interval. The computer science translation of these four criteria required the creation of a positive and a negative rule. The positive rule translates the fact that a bit is absent or present in the vector. The negative rule translates the fact that there must be at least one bit present or absent in a given interval. Three values can be attributed for each bit, " $\mathrm{n}$ " = present, "o" = absent, "x" = variable. The software generates a text file, which contains all spoligotypes sorted by family and PGG, and a specific file for each rule containing the spoligotypes which fulfilled the selection criteria. Rules are hierarchical, i.e. some rules are smooth and almost each spoligotype fulfils it (ex: T1 rule), whereas others are tight (ex: LAM12-Madrid1), hence a final multilevel classification scheme for each shared-type from the most precise to the less precise sub lineage/lineage label (ex: LAM3/LAM9/T1).

Secondly, an algorithm establishes the hierarchic links from the entry data file. This algorithm is based on a comparison of vector. The model (assumption) relies on an evolution that proceeds by deletion of a unique block of one to $n$ consecutive bits on the DR locus. For a given spoligotype, the algorithm finds all the potential offspring spoligotypes. The result is transferred into a file whose format is directly used by the BioLayout software [89]. Building a file for BioLayout looks like a simple task but it turns out to be a tedious and time-consuming task for file with hundreds of spoligotypes. This file cannot be built without software for thousands of spoligotypes, as it is the case for the SpolDB4 database project. The two developed algorithms are exponential, i.e. the time to sort data files and to generate Biolayout files increases with the size of 
the entry data file. As an example, a file with 1000 spoligotypes may take approximately 20 minutes to be sorted and 20 minutes to generate the Biolayout file. New spoligotype-recognition rules may be introduced as a dynamic process, either when new genotypes are discovered, to introduce new hypothesis, or to modify pre-existing rules.

\section{Definition of indices}

The global distribution of spoligotyping patterns was assessed within and between the eight studied continental regions: Africa, Central America, Europe, Far East Asia, Middle East and Central Asia, North America, Oceania, and South America. A slight modification in definition of $\mathrm{C} 1$ and $\mathrm{C} 2$ was introduced, i.e. a spreading Index SI $\geq 25$ instead of $\mathrm{SI} \geq 30$ is now required to define a clone as "epidemic". Briefly, the Spreading Index (SI) represents a mean number of occurences of a clone, independent of the setting (total $n^{\circ}$ of occurrences for this ST divided by the number of geographical areas where it is found). The reader should refer to Figure 2 of [26], or to Table 1 for full definition of $\mathrm{C} 1$ and $\mathrm{C} 2$.

\section{Availability}

SpolDB4 listing [see additional file 1] is available as supplemental material. A dedicated interactive website, SITVIT1 which will allow SpolDB4 (39525 genotypes) to be queried online is available [93]. In its research format SITVIT1 allows one to enter MLVA data and to automatically detect MLVA clusters [90]. The full list of investigators having contributed to SpolDBs since the origin of the project will also appear on the website. SpotClust results were extracted from [91].

\section{Quality control (QC)}

During the SpolDB4 project, we faced increased quality control problems due to an increased recruitment rate and had to exclude some datasets. A common problem was the systematic absence of one spacer on some membranes. These data sets were systematically excluded. Most of these problems were linked to manufacturing defaults in the commercialized membranes. All data sets were checked individually and sometimes audited on source results (autoradiography). Most investigators, to check their procedures, completed a QC form. International Guidelines to increase spoligotyping quality are in progress and will be reported elsewhere. As in all databases, we assume a reasonable ( 2 to $5 \%$ maximum) error rate in data points. However, the problem of QC in high throughput genotyping technique and database science technology is an emerging issue [92]. A list of STs whose distribution did not change between SpolDB3 and 4 is available upon request. These genotypes represent: (1) ongoing genotypes not detected because of no follow-up in a given area, (2) potentially extinct genotypes, (3) potential typing artefacts. Similarly as in SpolDB3, where
5 STs had been suppressed, 22 STs in SpolDB4 could be artefacts (ST422, 424, 425, 454, 456, 540, 547, 551, 553, $556,571,870,886,887,900,901,908,1270,1575$, $1608,1625,1896)$.

\section{Authors' contributions}

All authors contributed to the spoligotyping data contained in the database at various levels, by locally isolating, identifying clinical isolates, preparing DNA and genotyping clinically isolates of MTC and sending their results to the Pasteur Institute in Guadeloupe. Their relative contribution would be to tedious to mention here, however, they are all part of the paper because such population-based studies could not be done without adequate mycobacteriological diagnostics, i.e., isolation of clinical isolates, identification, drug-susceptibility testing, DNA extraction, genotyping and ultimately by sharing of data, hence without adequate reward of the numerous persons and labs involved in such analysis.

KB managed the SpolDB4 Information System, controlled data quality, did part of the supervised analysis, used SpolNet for Bioinformatical classification, compiled data synthesis. CS initiated the SpolDB project, established many of the contacts, recruited many of the investigators with NR, writing e-mails, checked the Information System developments helped by numerous Computer scientists (Philippe Leremon, Christel Delfino, Philippe Abdoul, Georges Valétudie, are warmly acknowledged). CS did part of the mining with $\mathrm{KB}$ and wrote the paper. JRD managed the PHRI New-York database and sent his data regularly to CS and KB. LR and WP were the two most "big account" data providers, together with AG. BL produced the maps (P. Waniez, Philcarto ${ }^{\varpi}$, IRD, France) and contributed to the statistical analysis.

\section{Additional material}

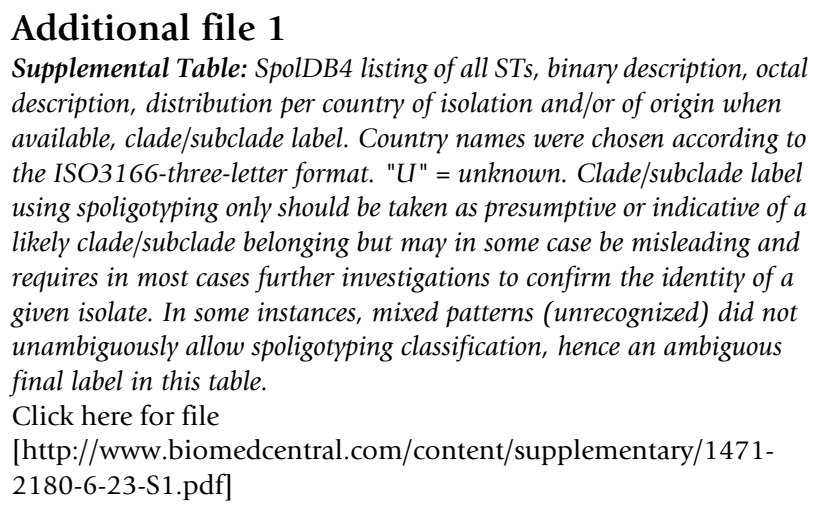
description, distribution per country of isolation and/or of origin when available, clade/subclade label. Country names were chosen according to the ISO3166-three-letter format. " $U "=$ unknown. Clade/subclade label using spoligotyping only should be taken as presumptive or indicative of a likely clade/subclade belonging but may in some case be misleading and requires in most cases further investigations to confirm the identity of a given isolate. In some instances, mixed patterns (unrecognized) did not unambiguously allow spoligotyping classification, hence an ambiguous final label in this table.

Click here for file

[http://www.biomedcentral.com/content/supplementary/14712180-6-23-S1.pdf] 


\section{Acknowledgements}

Dr. K. Brudey performed this work as part of her doctoral thesis. She has been working at the Institut Pasteur de Guadeloupe for the last 4 years. Her research focuses on molecular epidemiology, genotyping methods and databases building of Mycobacterium tuberculosis complex.

This paper was written as part of the EU Concerted Action project QLK2CT-2000-00630. The "Unité de la Tuberculose et des Mycobactéries" is supported by the Réseau International des Instituts Pasteur et Instituts Associés, Institut Pasteur, Paris, France. We also would like to thank many investigators whose published or unpublished datas were included in SpoIDB4, and others who sent a limited number of unpublished spoligotypes.

Our particular thanks go to (in alphabetical order):

R. Aga (USA), N. Ahmed (India). M. Behr (Canada), M. L. Boschiroli (France), F. Boulahbal (Algeria), E. Bouza (Spain), M. Cardodo-Oelemann (Brazil), G. Cangelosi (USA), U. Dahle (Norway), D. Cousins (Australia), J. T. Crawford (USA), S. David. (Portugal), O. Dellagostin (Brazil), E. Desmond (USA), R. Diaz (Cuba), J. Douglas (Hawaii, USA), F. Drobniewski (United Kingdom), R. Durmaz (Turkey), G. Engelmann (Germany), D. ElBaghdadi (Morocco), P. Easterbrook (United Kingdom), G. Fadda (Italy), P. Freidlin (Israel), A. Gibson (United Kingdom), W. Githui (Kenya), N. Guessend (Ivory Coast), W. Haas (Germany), G. Källenius (Sweden), T. Koivula (Sweden), A. Kwara (USA), C. Mammina (Italy), M. C. Martins (Brazil), T. McHugh (United Kingdom), T. Matsumoto (Japan), N. Morcillo (Argentina), A. Nastasi (Italy), A. Nehrlich (Germany), D. N'guyen (Canada), G. Orefici (Italy), R. Oohata (Japan), J. W. Pape (Haiti), L. Parsons (USA), T. Quitugua (USA), M. Ridell (Sweden), A. Riveira (Philippines), M. H. Ferez Saad (Brazil), L. Sechi (Sardinia, Italy), M. Shemko (United Kingdom), H. Soini (Finland), Y. Sun (Singapore), P. Supply (France), A. Tada (Japan), H. Takiff (Venezuela), A. Vaughan (New Zealand), J. de Waard (Venezuela), G. Yanling (China), S. Zanetti (Italy), A. van der Zanden (Netherlands), M. Zanini (Brazil), A. Zink (Germany). The authors apologize for any names that may have been omitted unwillingly. Two anonymous reviewers helped to improve the manuscript and are also warmly acknowledged.

\section{References}

I. Kaufmann SHE, Schaible UE: I 00th anniversary of Robert Koch's Nobel Prize for the discovery of the tubercle bacillus. Trends Microbiol 2005, I 3( I 0):469-475.

2. Mostowy S, Behr MA: The origin and evolution of Mycobacterium tuberculosis. Clin Chest Med 2005, 26:207-216.

3. Groenen PMA, Bunschoten AE, vanSoolingen D, vanEmbden JDA: Nature of DNA polymorphism in the direct repeat cluster of Mycobacterium tuberculosis; application for strain differentiation by a novel typing method. Mol Microbiol 1993, I0(5): I057-1065.

4. Jansen R, van Embden JD, Gaastra W, Schouls LM: Identification of a novel family of sequence repeats among prokaryotes. Genomics 2002, 6( I):23-33.

5. Mojica FJ, Diez-Villasenor C, Garcia-Martinez J, Soria E: Intervening sequences of regularly spaced prokaryotic repeats derive from foreign genetic elements. J Mol Evol 2005, 60(2): I 74- I 82.

6. Pourcel C, Salvignol G, Vergnaud G: CRISPR elements in Yersinia pestis acquire new repeats by preferential uptake of bacteriophage DNA, and provide additional tools for evolutionary studies. Microbiology 2005, I 5 I (Pt 3):653-663.

7. Gori A, Bandera A, Marchetti G, Degli Esposti A, Catozzi L, Nardi GP, Gazzola L, Ferrario G, van Embden JD, van Soolingen D, et al.: Spoligotyping and Mycobacterium tuberculosis. Emerg Infect Dis 2005, I I(8): I242-I248.

8. Frothingham R, Meeker-O'Connell WA: Genetic diversity in the Mycobacterium tuberculosis complex based on variable numbers of tandem DNA repeats. Microbiol 1998, I44: I I89-II 96.
9. Supply P, Mazars E, Lesjean S, Vincent V, Gicquel B, Locht C: Variable human minisatellite-like regions in the Mycobacterium tuberculosis genome. Mol Microbiol 2000, 36:762-771.

10. Lindstedt BA: Multiple-locus variable number tandem repeats analysis for genetic fingerprinting of pathogenic bacteria. Electrophoresis 2005, 26(13):2567-2582.

II. Hirsh AE, Tsolaki AG, DeRiemer K, Feldman MW, Small PM: Stable association between strains of Mycobacterium tuberculosis and their human host populations. Proc Natl Acad Sci USA 2004, I 0 I ( I 4):487| -4876.

12. Sola C, Filliol I, Legrand E, Mokrousov I, Rastogi N: Mycobacterium tuberculosis phylogeny reconstruction based on combined numerical analysis with IS IS6 I I0, VNTR and DR-based spoligotyping suggests the existence of two new phylogeographical clades. I Mol Evol I08I, 53:680-689.

13. Supply P, Warren RM, Banuls AL, Lesjean S, Van Der Spuy GD, Lewis LA, Tibayrenc M, Van Helden PD, Locht C: Linkage disequilibrium between minisatellite loci supports clonal evolution of Mycobacterium tuberculosis in a high tuberculosis incidence area. Mol Microbiol 2003, 47(2):529-538.

14. Mokrousov I, Ly HM, Otten T, Lan NN, Vyshnevskyi B, Hoffner S, Narvskaya O: Origin and primary dispersal of the Mycobacterium tuberculosis Beijing genotype: clues from human phylogeography. Genome Res 2005, I 5(1 0): 1357-1364.

I5. Fabre M, Koeck JL, Le Fleche P, Simon F, Herve V, Vergnaud G, Pourcel $C$ : High genetic diversity revealed by variable-number tandem repeat genotyping and analysis of hsp65 gene polymorphism in a large collection of "Mycobacterium canettii" strains indicates that the $M$. tuberculosis complex is a recently emerged clone of "M. canettii". J Clin Microbiol 2004, 42(7):3248-3255.

16. Cruciani F, Santolamazza P, Shen P, Macaulay V, Moral P, Olckers A, Modiano D, Destro-Bisol G, Coia $V$, et al.: A back migration from Asia to sub-Saharan Africa is supported by high- resolution analysis of human Y-chromosome haplotypes. Am J Hum Genet 2002, 70(5): I| $197-1214$.

17. Kinsella RJ, Fitzpatrick DA, Creevey C], Mclnerney JO: Fatty acid biosynthesis in Mycobacterium tuberculosis: lateral gene transfer, adaptive evolution, and gene duplication. Proc Natl Acad Sci USA 2003, I 00( I 8): 10320-10325.

18. Klovdahl AS, Graviss EA, Yaganehdoost A, Ross MW, Wanger A, Adams G], Musser JM: Networks and tuberculosis: an undetected community outbreak involving public places. Soc Sci Med 200I, 52(5):68I-694.

19. Hopcroft J, Khan O, Kulis B, Selman B: Tracking evolving communities in large linked networks. Proc Natl Acad Sci USA 2004 I 0 I (Suppl I):5249-5253. Epub 2004 Feb 5242.

20. Avise JC, Arnold J, Ball RM, Bermingham E, Lamb T, Neigel JE, Reeb CA, Saunders NC: Intraspecific phylogeography: the mitochondrial DNA bridge between population genetics and systematics. Ann Rev Ecol Syst 1987, I 8:489-522.

21. Knowles LL: The burgeoning field of statistical phylogeography. J Evol Biol 2004, I 7(I): I-I0.

22. van Belkum A, Struelens M, deVisser A, Verbrugh H, Tibayrenc $M$ : Role of genomic typing in Taxonomy, evolutionary genetics, and microbial epidemiology. Clin Microbiol Rev 200I, I 4(3):547-560.

23. Sola C, Devallois A, Horgen L, Maïsetti J, Filliol I, Legrand E, Rastogi $\mathrm{N}$ : Tuberculosis in the Caribbean: using spacer oligonucleotide typing to understand strain origin and transmission. Emerg Inf Dis 1999, 5(3):404-414.

24. Sola C, Filliol I, Guttierez C, Mokrousov I, Vincent V, Rastogi N: Spoligotype database of Mycobacterium tuberculosis: Biogeographical distribution of shared types and epidemiological and phylogenetic perspectives. Emerg Inf Dis 200I, 7:390-396.

25. Filliol I, Driscoll JR, Van Soolingen D, Kreiswirth BN, Kremer K, Valétudie G, Anh DD, Barlow R, Banerjee D, Bifani PJ, et al.: Global distribution of Mycobacterium tuberculosis spoligotypes. Emerge Inf Dis 2002, 8(I I): I347-1350.

26. Filliol I, Driscoll JR, van Soolingen D, Kreiswirth BN, Kremer K, Valetudie G, Dang DA, Barlow R, Banerjee D, Bifani PJ, et al.: Snapshot of moving and expanding clones of Mycobacterium tuberculosis and their global distribution assessed by spoligotyping in an international study. J Clin Microbiol 2003, 4 I (5): I 963- I970. 
27. Sebban M, Mokrousov I, Rastogi N, Sola C: A Data-mining approach to Spacer Oligonucleotide Typing of Mycobacterium tuberculosis. Bioinformatics 2002, I 8:235-243.

28. Gutacker MM, Mathema B, Soini H, Shashkina E, Kreiswirth BN, Graviss EA, Musser JM: Single-Nucleotide PolymorphismBased Population Genetic Analysis of Mycobacterium tuberculosis Strains from 4 Geographic Sites. I Infect Dis 2006, 193(I): $121-128$

29. Filliol I, Motiwala AS, Cavatore M, Qi W, Hazbon MH, Bobadilla de Valle M, Fyfe J, Garcia-Garcia L, Rastogi N, Zozio T, et al.: The Global Phylogeny of Mycobacterium tuberculosis based on single nucleotide polymorphism (SNP) analysis : insights into tuberculosis evolution, phylogenetic accuracy of other DNA fingerprinting systems and recommendations for a minimal standard SNP set. J Bacteriol 2006 in press.

30. Warren RM, Streicher EM, Sampson SL, Van Der Spuy GD, Richardson M, Nguyen D, Behr MA, Victor TC, Van Helden PD: Microevolution of the Direct Repeat Region of Mycobacterium tuberculosis: Implications for Interpretation of Spoligotyping Data. I Clin Microbiol 2002, 40:4457-4465.

31. Quitugua TN, Seaworth BJ, Weis SE, Taylor JP, Gillette JS, Rosas II, Jost KC Jr, Magee DM, Cox RA: Transmission of drug-resistant tuberculosis in Texas and Mexico. I Clin Microbiol 2002 40:2716-2724

32. vanSoolingen $D$, vanderZanden AGM, deHaas PEW, Noordhoek GT, Kiers A, Foudraine NA, Portaels F, Kolk AHJ, Kremer K, vanEmbden JDA: Diagnosis of Mycobacterium microti infections among humans by using novel genetic markers. J Clin Microbiol 1998 , 36(7): $1840-1845$

33. Aranaz A, Liebana E, Gomez-Mampaso E, Galan JC, Cousins D, Ortega A, Blazquez J, Baquero F, Mateos A, Suarez G, et al:: Mycobacterium tuberculosis subsp. caprae subsp. nov.: a taxonomic study of a new member of the Mycobacterium tuberculosis complex isolated from goats in Spain. Int J Syst Bacteriol 1999 , 49:1263-1273

34. van der Zanden AG, Kremer K, Schouls LM, Caimi K, Cataldi A, Hulleman A, Nagelkerke NJ, van Soolingen D: Improvement of differentiation and interpretability of spoligotyping for Mycobacterium tuberculosis complex isolates by introduction of new spacer oligonucleotides. I Clin Microbiol 2002 40(12):4628-4639.

35. Brudey K, Gutierrez MC, Vincent V, Parsons LM, Salfinger M, Rastogi N, Sola C: Mycobacterium africanum Genotyping Using Novel Spacer Oligonucleotides in the Direct Repeat Locus. J Clin Microbiol 2004, 42(I I):5053-5057.

36. Pritchard JK, Stephens M, Donnelly P: Inference of population structure using multilocus genotype data. Genetics 2000 , I 55(2):945-959.

37. Structure [http://pritch.bsd.uchicago.edu]

38. Vijaya-Bhanu $N$, van Soolingen D, van Embden JDA, Dar L, Pandey RM, Seth P: Predominance of a novel Mycobacterium tuberculosis genotype in the Delhi region of India. Tuberculosis 2002 , 82(213): $105-1 \mid 2$.

39. Singh UB, Suresh N, Vijaya Bhanu N, Arora J, Pant H, Sinha S, Aggarwal RC, Singh S, Pande JN, Sola C, et al.: Predominant Tuberculosis Spoligotypes, Delhi, India. Emerg Infect Dis 2004 I 0(6): I I38-| | 42

40. McHugh TD, Batt SL, Shorten RJ, Gosling RD, Uiso L, Gillespie SH: Mycobacterium tuberculosis lineage : a naming of the parts. Tuberculosis (Edinb) 2005, 85:127-136.

41. Douglas JT, Qian L, Montoya JC, Musser JM, Van Embden JD, Van Soolingen D, Kremer K: Characterization of the Manila Family of Mycobacterium tuberculosis. J Clin Microbiol 2003, 4I(6):2723-2726

42. Namwat $W$, Luangsuk $P$, Palittapongarnpim P: The genetic diversity of Mycobacterium tuberculosis strains in Thailand studied by amplification of DNA segments containing direct repetitive sequences. Int J Tuberc Lung Dis 1998, 2(2): I53-159.

43. Kovalev SY, Kamaev EY, Kravchenko MA, Kurepina NE, Skorniakov SN: Genetic analysis of Mycobacterium tuberculosis strains isolated in Ural region, Russian federation, by MIRU-VNTR genotyping. Int J Tuberc Lung Dis 2005, 9(7):746-752.

44. Zozio T, Allix C, Gunal S, Saribas Z, Alp A, Durmaz R, Fauville-Dufaux M, Rastogi N, Sola C: Genotyping of Mycobacterium tuberculosis in two cities of Turkey suggests a phylogeographical specificity for the LAM7 lineage. BMC Microbiol 2005, 5(44):
45. Niobe-Eyangoh SN, Kuaban C, Sorlin P, Cunin P, Thonnon J, Sola C, Rastogi N, Vincent V, Gutierrez MC: Genetic biodiversity of Mycobacterium tuberculosis complex strains from patients with pulmonary tuberculosis in Cameroon. I Clin Microbiol 2003, 4 I (6):2547-2553.

46. Ngo Niobe-Eyangoh S, Kuaban C, Sorlin P, Cunin P, Thonnon J, Sola C, Rastogi N, Vincent V, Gutierrez MC: Genetic biodiversity of Mycobacterium tuberculosis complex strains from patients with pulmonary tuberculosis in Cameroon. I Clin Microbiol 2003, 4 I (6):2547-2553.

47. Easterbrook PJ, Gibson A, Murad S, Lamprecht D, Ives N, Ferguson

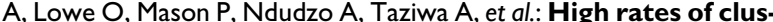
tering of strains causing tuberculosis in Harare, Zimbabwe: a molecular epidemiological study. J Clin Microbiol 2004, 42( I 0):4536-4544

48. Garcia de Viedma D, Bouza E, Rastogi N, Sola C: Analysis of Mycobacterium tuberculosis genotypes in Madrid : description of two new families specific to Spain-related settings. J Clin Microbiol 2005, 43: 1797-1806.

49. Sola C, Ferdinand S, Mammina C, Nastasi A, Rastogi N: Genetic Diversity of Mycobacterium tuberculosis in Sicily Based on Spoligotyping and Variable Number of Tandem DNA Repeats and Comparison with a Spoligotyping Database for Population-Based Analysis. J Clin Microbiol 200I, 39(4): I559- 1565

50. Hermans PW, Messadi F, Guebrexhaber $H$, Soolingen Dv, Haas PEWd, Heersma H, Neeling Hd, Ayoub A, Portaels F, Frommel D, et al.: Analysis of the Population Structure of Mycobacterium tuberculosis in Ethiopia, Tunisia and the Netherlands: usefulness of DNA Typing for Global Tuberculosis Epidemiology. J ID |995, I7 I:|504-1513.

5I. Lari N, Rindi L, Sola C, Bonanni D, Rastogi N, Tortoli E, Garzelli C: Genetic diversity determined on the basis of katG463 and gyrA95 polymorphisms, spoligotying, and IS6 I I0 typing of the Mycobacterium tuberculosis complex isolates from Italy. J Clin Microbiol 2005, 43:1617-1624.

52. Ohata R, Tada A: [Beijing family and other genotypes of Mycobacterium tuberculosis isolates in Okayama district]. Kekkaku 2004, 79(2):47-53

53. Sola C, Zozio T, Ellermeier C, Sajduda A, Naumann L, Nguyen D, Behr $M$, de Haas $P$, vanH est $R$, van Soolingen $D$, et al:: The presumed origin of a recent tuberculosis outbreak among the Inuit community of Nunavik. 26th Annual Congress of the European Society of Mycobacteriology:2005: Istanbul, Turkey, June 25-29th 2005 2005:9l. Abstract Book, P-27 poster

54. Gutacker MM, Smoot JC, Migliaccio CA, Ricklefs SM, Hua S, Cousins DV, Graviss EA, Shashkina E, Kreiswirth BN, Musser JM: GenomeWide Analysis of Synonymous Single Nucleotide Polymorphisms in Mycobacterium tuberculosis Complex Organisms. Resolution of genetic relationships among closely related microbial strains. Genetics 2002, I 62(4): I533-I543.

55. Baker L, Brown T, Maiden MC, Drobniewski F: Silent nucleotide polymorphisms and a phylogeny for Mycobacterium tuberculosis. Emerg Inf Dis 2004, I 0(9): I 568-I577.

56. Dale JW, Al-Ghusein H, Al-Hasmi S, Butcher PD, Dickens A, Drobniewski F, Forbes KJ, Gillespie S, Lamprecht D, McHugh TD, et al: Evolutionary relationships amongst isolates of Mycobacterium tuberculosis with few copies of IS 6II0. J Bacteriol 2003, I 85(8):2555-2562

57. Warren RM, Victor TC, Streicher EM, Richardson M, van der, Spuy GD, Johnson R, Chihota VN, Locht C, Supply P, van Helden PD: Clonal expansion of a globally disseminated lineage of Mycobacterium tuberculosis with low IS6 I I 0 copy numbers. J Clin Microbiol 2004, 42( 1 2):5774-5782

58. Soini H, Pan X, Teeter L, Musser JM, Graviss EA: Transmission dynamics and molecular characterization of Mycobacterium tuberculosis isolates with low copy numbers of IS6 IIO [In Process Citation]. J Clin Microbiol 200I, 39(I):217-22I.

59. Berkhin P: Survey of clustering data mining techniques, Accrue Software,. 2002. 2002. http://wwwaccruecom/products/ rp_cluster_reviewpdf

60. Vitol I, Driscoll J, Kurepina N, Kreiswirth B, Bennett K: SpotClust a tool to cluster spoligotype data for tuberculosis evolution and epidemiology. Recomb 2005: Cambrdige, Ma, May 14-I8; 2005 2005 
6I. Duchene V, Ferdinand S, Filliol I, Guégan JF, Rastogi N, Sola C: Phylogenetic reconstruction of the Mycobacterium tuberculosis complex within four settings of the Caribbean region : tree comparative analysis and first appraisal on their phylogeography. Infect Gen Evol 2004, 4:5-14.

62. Sola C, Rastogi N: Genetic description and frequency maps of some major families of Mycobacterium tuberculosis. In Molecular Epidemiology and Population Genetics of Tuberculosis Edited by: Ngeow YF, SF Yap. Kuala Lumpur: Academy of Sciences of Malaysia; 2006:23-68.

63. Qian L, Embden JDAv, Zanden AGMvd, Weltevreden EF, Duanmu H, Douglas JT: Retrospective analysis of the Beijing family of Mycobacterium tuberculosis in preserved lung tissues. J Clin Microbiol 1999, 37(2):47I-474.

64. Glynn JR, Whiteley J, Bifani PJ, Kremer K, Van Soolingen D: Worldwide Occurrence of Beijing/W Strains of Mycobacterium tuberculosis: A Systematic Review. Emerg Infect Dis 2002, 8(8):843-849.

65. Phyu S, Jureen R, Ti T, Dahle UR, Grewal HM: Heterogeneity of Mycobacterium tuberculosis isolates in Yangon, Myanmar. Clin Microbiol 2003, 4 I ( I 0):4907-4908.

66. Kulkarni S, Sola C, Filliol I, Rastogi N, Kadival G: Spoligotyping of Mycobacterium tuberculosis isolates from patients with pulmonary tuberculosis in Mumbai, India. Res Microbiol 2005, I 56(4):588-596. Epub 2005 Feb 2007.

67. Gascoyne-Binzi DM, Barlow RE, Essex A, Gelletlie R, Khan MA, Hafiz S, Collyns TA, Frizzell R, Hawkey PM: Predominant VNTR family of strains of Mycobacterium tuberculosis isolated from South Asian patients. Int J Tuberc Lung Dis 2002, 6(6):492-496.

68. Farnia P, Mohammadi F, Masjedi MR, Varnerot A, Zarifi AZ, Tabatabee J, Douraghei M, Ghazisaeedi K, Mansorri D, Bahadori M, et al.: Evaluation of tuberculosis transmission in Tehran: using RFLP and spoligotyping methods. J Infect 2004, 49(2):94-101.

69. Kempf MC Dunlap NE, Lok KH, Benjamin WH Jr, Keenan NB, Kimerling ME: Long-term molecular analysis of tuberculosis strains in Alabama, a state characterized by a largely indigenous, low-risk population. J Clin Microbiol 2005, 43(2):870-878.

70. Liens B, Sola C, Brudey K, Rastogi N, and the european co-investigators of the SITVIT consortium: Spatial Genetics and the spreading history of tuberculosis in Europe. 26th Annual Congress of the European Society for Mycobacteriology June 26th-29th 2005: Istanbul, Turkey, 26-29 Jun 2005 2005:65. Abstract Book, P-I poster

71. Gutierrez MC, Brisse S, Brosch R, Fabre M, Omais B, Marmiesse M, Supply P, Vincent V: Ancient origin and gene mosaicism of the progenitor of Mycobacterium tuberculosis. PLOS Pathog 2005 , I(I): e5.

72. Cruciani F, Santolamazza P, Shen P, Macaulay V, Moral P, Olckers A, Modiano D, Holmes S, Destro-Bisol G, Coia V, et al.: A back migration from Asia to sub-Saharan Africa is supported by highresolution analysis of human $\mathrm{Y}$-chromosome haplotypes. Am J Hum Genet 2002, 70(5): I 197-12/4.

73. Mokrousov I, Ly HM, Otten T, Lan NLT, Vyshnevskyi B, Hoffner S, Narvskaia OV: Origin and primary dispersal of the Mycobacterium tuberculosis Beijing genotype : clues from human phylogeography. Genom Res 2005, I 5(10): I357-I 364.

74. Shamputa IC, Rigouts L, Eyongeta LA, El Aila NA, van Deun A, Salim $\mathrm{AH}$, Portaels $\mathrm{F}$ : Frequency of mixed $\boldsymbol{M}$. tuberculosis strains in pulmonary tuberculosis from a high incidence setting. Third meeting of concerted action project : new generation genetic markers and techniques for the epidemiology and control of tuberculosis: 2003; Prague 2003:22.

75. Feil EJ, Smith JM, Enright MC, Spratt BG: Estimating recombinational parameters in Streptococcus pneumoniae from multilocus sequence typing data. Genetics 2000, I 54(4): I439-1450.

76. Gibson A, Brown T, Baker L, Drobniewski F: Can I5-Locus Mycobacterial Interspersed Repetitive Unit-Variable-Number Tandem Repeat Analysis Provide Insight into the Evolution of Mycobacterium tuberculosis? Appl Environ Microbiol 2005, 7I(I 2):8207-82 I3.

77. Sun YJ, Bellamy R, Lee AS, Ng ST, Ravindran S, Wong SY, Locht C Supply P, Paton NI: Use of Mycobacterial Interspersed Repetitive Unit-Variable-Number Tandem Repeat Typing To Examine Genetic Diversity of Mycobacterium tuberculosis in Singapore. J Clin Microbiol 2004, 42(5): 1986-1993.
78. Blackwood KS, Al-Azem A, Elliott LJ, Hershfield ES, Kabani AM: Conventional and molecular epidemiology of tuberculosis in Manitoba. BMC Infect Dis 2003, 3(1):18.

79. Scott AN, Menzies D, Tannenbaum T, Thibert L, Kozak R, Joseph L, Schwartzman K, Behr MA: Sensitivities and Specificities of Spoligotyping and Mycobacterial Interspersed Repetitive UnitVariable-Number Tandem Repeat Typing methods for studying Molecular epidemiology of Tuberculosis. J Clin Microbiol 2005, 43:89-94.

80. Malik AN, Godfrey-Faussett P: Effects of genetic variability of Mycobacterium tuberculosis strains on the presentation of disease. Lancet Infect Dis 2005, 5(3): I74- 183.

8I. Smith NH, Dale J, Inwald J, Palmer S, Gordon SV, Hewinson RG, Maynard Smith J: The population structure of Mycobacterium bovis in Great Britain : clonal expansion. published online before print December I st, 2003. Proc Natl Acad Sci USA 2003.

82. van Soolingen D, Qian L, de Haas PEW, Douglas JT, Traore H, Portaels F, Qing HZ, Enkhsaikan D, Nymadawa P, van Embden JDA: Predominance of a Single Genotype of Mycobacterium tuberculosis in Countries of East Asia. J Clin Microbiol 1995, 33:3234-3238.

83. SpolDB4 [http://www.pasteur-guadeloupe.fr/tb/spoldb4]

84. Kamerbeek J, Schouls L, Kolk A, van Agterveld M, Van Soolingen D, Kuijper S, Bunschoten A, Molhuizen H, Shaw R, Goyal M, et al:: Simultaneous detection and strain differentiation of Mycobacterium tuberculosis for diagnosis and epidemiology. J Clin Microbiol 1997, 35:907-9|4

85. van Embden JDA, van Gorkom T, Kremer K, Jansen R, van der Zeijst BAM, Schouls LM: Genetic variation and evolutionary origin of the Direct repeat locus of Mycobacterium tuberculosis complex bacteria. I Bacteriol 2000, 182:2393-240I.

86. Dale JW, Brittain D, Cataldi AA, Cousins D, Crawford JT, Driscoll J, Heersma H, Lillebaek T, Quitugua T, Rastogi N, et al:: Spacer oligonucleotide typing of Mycobacterium tuberculosis : recommendations for standardized nomenclature. Int J Tuberc Lung Dis 2001, 5:216-219.

87. Sreevatsan S, Pan X, Stockbauer K, Connell N, Kreiswirth B, Whittam $T$, Musser J: Restricted structural gene polymorphism in the Mycobacterium tuberculosis complex indicates evolutionarily recent global dissemination. Proc Natl Acad Sci USA 1997, 94:9869-9874.

88. Soini H, Pan X, Amin A, Graviss EA, Siddiqui A, Musser JM: Characterization of Mycobacterium tuberculosis isolates from patients in Houston, Texas, by spoligotyping. J Clin Microbiol 2000, 38(2):669-676.

89. Enright AJ, Ouzounis CA: BioLayout- an automatic graph layout algorithm for similarity visualization. Bioinformatics 2001 , I 7(9):853-854.

90. Supply P, Lesjean S, Savine E, Kremer K, van Soolingen D, Locht C: Automated high-throughput genotyping for study of global epidemiology of Mycobacterium tuberculosis based on mycobacterial interspersed repetitive units. J Clin Microbiol 200I, 39:3563-357I.

91. SpotClust [http://www.rpi.edu/ bennek/EpiResearch]

92. Ewen KR, Bahlo M, Treloar SA, Levinson DF, Mowry B, Barlow JW, Foote SJ: Identification and analysis of error types in highthroughput genotyping. Am J Hum Genet 2000, 67(3):727-736.

93. Institut Pasteur de la Guadeloupe [http://www.pasteur-guadeloupe.fr/ tb]. 